\title{
ANÁLISE DE ADERÊNCIA DO PLANO DE GESTÃO DE LOGÍSTICA SUSTENTÁVEL E DAS AÇÕES PROPOSTAS NA AGENDA A3P: UM ESTUDO DE CASO NO CEFET/RJ
}

\section{ARTIGO ORIGINAL}

HAUSSMANN, Antonio Marcio Freitas ${ }^{1}$, FRANÇA, Sergio Luiz Braga ${ }^{2}$

HAUSSMANN, Antonio Marcio Freitas. FRANÇA, Sergio Luiz Braga. Análise de aderência do plano de gestão de logística sustentável e das ações propostas na agenda a3p: um estudo de caso no CEFET/RJ. Revista Científica Multidisciplinar Núcleo do Conhecimento. Ano. 06, Ed. 12, Vol. 02, pp. 05-47. Dezembro de 2021. ISSN: 2448-0959,

Link de

acesso: https://www.nucleodoconhecimento.com.br/engenharia-de-

producao/logistica-sustentavel, DOI:

10.32749/nucleodoconhecimento.com.br/engenharia-de-producao/logisticasustentavel

\section{RESUMO}

As Instituições Federais de Ensino possuem um importante papel no desenvolvimento e na formação da sociedade, bem como são também fundamentais na disseminação da conscientização pública à cerca da sustentabilidade nas áreas de ensino, pesquisa, cursos de extensão voltados para a comunidade e nas operações realizadas em suas unidades. Esta pesquisa tem o objetivo de analisar a aderência do Plano de Gestão de Logística Sustentável (PLS) do Centro Federal de Educação Tecnológica Celso

1 Pós-graduação (lato sensu) em Administração Pública, Graduação em Ciências Contábeis. ORCID: 0000-0001-6351-2431.

2 Orientador. Doutorado em Engenharia Civil (UFF), Mestrado em Engenharia Civil (UFF), Graduação em Engenharia Civil (UFF) ORCID: https://orcid.org/0000-00031783-3167. 
Suckow da Fonseca (CEFET/RJ) e as ações propostas da Agenda Ambiental na Administração Pública (A3P), visando fornecer informações que possam subsidiar ajustes, melhorias à sua implementação e responder o seguinte questionamento: Como melhorar a implementação do PLS em uma instituição de ensino de acordo com as legislações ambientais vigentes e seguindo as ações propostas na Agenda A3P? Para alcançar os objetivos foi realizada uma pesquisa qualitativa de finalidade exploratória e de natureza aplicada, com base em um estudo de caso por meio de entrevista semiestruturada e aplicação de questionários a gestores, professores e técnicos administrativos das unidades da instituição objeto de estudo. Os principais resultados da pesquisa estão relacionados com a necessidade de uma melhor divulgação das ações propostas pela Agenda A3P que foram implementadas no CEFET/RJ, além da necessidade de implementação de outras ações, como: a substituição de mobiliários por outros mais ergonômicos, a melhoria da acessibilidade, automatização da iluminação nas edificações, instalação de paredes de proteção contra ruídos externos nas salas de trabalho e de aula, instalação de painéis fotovoltaicos, entre outros. Por fim, conclui-se a importância das Instituições Federais de Ensino na implantação do PLS e da Agenda A3P de forma eficiente, visando reduzir desperdícios e contribuir com a mudança da cultura organizacional em prol de impactos positivos para a sociedade e um futuro melhor para as próximas gerações.

Palavras-chave: Instituição Federal de Ensino, Plano de Gestão de Logística Sustentável (PLS), Agenda Ambiental na Administração Pública (A3P), Legislação Ambiental.

\section{INTRODUÇÃO}

O crescimento populacional e a resultante demanda por produtos originados no início da década de 50 colaboraram para o crescimento das atividades industriais e para o avanço do capitalismo. Esse progresso trouxe inúmeras consequências para o meio ambiente, como: a poluição, o acúmulo de lixo, a aglomeração urbana, um grande volume de esgoto, dentre outras. Com isso, o meio ambiente vem sendo transformado de forma progressiva em função do desgaste dos recursos naturais, da intensidade 
de sua utilização muitas vezes acima do seu poder de regeneração e em função de um sistema econômico baseado no acúmulo de riquezas.

O senso de proteção ambiental tornou-se muito popular, mas ainda há uma grande necessidade de se dar um maior foco na questão da sustentabilidade. As empresas buscam implementar em suas atividades práticas sustentáveis com a finalidade de aumentar seus ganhos financeiros e sua visibilidade no mercado. Este aumento de visibilidade pode influenciar a sociedade de maneira positiva. Os professores, gestores e empreendedores de novas empresas são componentes importantes na mudança que o mundo precisa para se tornar mais sustentável (MOURA et al., 2019).

Diante deste cenário os gestores e as instituições públicas devem rever seus modelos de gestão e os seus padrões de consumo procurando introduzir a sustentabilidade em suas políticas de gestão e conciliar a igualdade entre as dimensões econômica, ambiental e social (HELBERT, 2019). A Administração Pública exerce grande responsabilidade por um mundo mais sustentável. As instituições públicas devem buscar a mudança de hábitos e atitudes internas, promovendo uma nova cultura institucional. Hoje o Estado assume um novo papel, o de "promotor da Responsabilidade Socioambiental". Em 31 de agosto de 1981 a lei no 6938 criou a Política Nacional do Meio Ambiente (PNMA) que estabeleceu um marco inicial para as políticas públicas ligadas ao meio ambiente resultando na criação do Sistema Nacional do Meio Ambiente (SISNAMA) e do Conselho Nacional do Meio Ambiente (CONAMA).

Em 2006, o governo federal em uma tentativa de reduzir os problemas causados pelo descarte indevido de produtos instituiu através do Decreto n 5.940 de 25 de outubro de 2006 que todos os órgãos e entidades da administração pública federal direta e indireta fizessem a separação dos resíduos recicláveis e destinassem às associações e cooperativas dos catadores de materiais recicláveis (MMA, 2020a). Em 2010, através da Lei no 12.305 de 02 de agosto de 2010 foi instituída a Política Nacional de Resíduos Sólidos (PNRS) que adotou a responsabilidade compartilhada dos 
geradores de resíduos (pessoas físicas e jurídicas), tornando todos responsáveis pela separação e pelo gerenciamento adequado dos resíduos sólidos gerados.

No final de 2012, a prática da gestão socioambiental foi introduzida nos órgãos da administração pública federal através do Decreto № 7.746 de 05 de junho de 2012 (alterado pelo Decreto 9.178 de 23 de outubro de 2017) que obriga os órgãos a elaborar e implementar o Plano de Gestão de Logística Sustentável (PLS). Para Helbert (2019), a importância do estudo de logística com ênfase na sustentabilidade em órgãos públicos se dá pela necessidade constante de redução de gastos que resulta em um melhor gerenciamento do dinheiro público e em uma melhor prestação dos serviços para o cidadão.

As instituições de ensino, especificadamente as de ensino superior, possuem um importante papel no desenvolvimento de futuras sociedades sustentáveis sendo responsáveis pela divulgação do conhecimento na sociedade (TRIGO; LIMA; OLIVEIRA, 2014). É necessário que estas instituições incorporem princípios e práticas de sustentabilidade, iniciando um processo de conscientização que consiga atingir docentes, funcionários e alunos ou tomando decisões importantes sobre planejamento, treinamento, operações ou atividades comuns em suas áreas (TAUCHEN; BRANDLI, 2006). Sendo assim, é fundamental a aceitação e a colaboração de todos os stakeholders envolvidos no processo de gestão pública sustentável de um Instituto de Ensino Superior (IES): Governo, estudantes, docentes, os técnicos administrativos, os gestores públicos da instituição e os funcionários terceirizados. Só assim o processo terá êxito (BRITO, 2017).

A presente pesquisa é motivada pela responsabilidade que temos como cidadãos nos dias de hoje com a preservação do meio ambiente que em longo prazo resultará em um futuro melhor para as próximas gerações e pela importância que as instituições de ensino têm na formação de cidadãos, visando uma sociedade ética e sustentável. Para isso é necessário que as instituições de ensino implantem o PLS e a Agenda Ambiental na Administração Pública (A3P) de forma eficiente e que consigam conscientizar a maioria dos envolvidos no processo. Partindo do entendimento que as 
Instituições Federais de Ensino (IFEs) também são peças fundamentais neste processo chega-se ao seguinte questionamento: Como melhorar a implementação do PLS em uma instituição de ensino de acordo com as legislações ambientais vigentes e seguindo as ações propostas na Agenda A3P?

Desta forma a pesquisa tem como objetivo geral analisar a aderência do PLS do CEFET/RJ e as ações propostas da A3P, visando fornecer informações que possam subsidiar ajustes e melhorias à sua implementação. Como resultado, a pesquisa busca fornecer melhorias de técnicas e/ou de procedimentos gerenciais já existentes. Este trabalho poderá servir como um documento base para outras organizações e instituições de ensino que queiram implantar o PLS e a Agenda A3P, respeitando suas especificidades próprias.

\section{FUNDAMENTAÇÃO TEÓRICA}

\subsection{SUSTENTABILIDADE NA ADMINISTRAÇÃO PÚBLICA}

O conceito de desenvolvimento sustentável surgiu inicialmente em Estocolmo no ano de 1972, na Conferência das Nações Unidas sobre o Homem e o Meio Ambiente (MUNCK; SOUZA; ZAGUI, 2012). Em 1983, a Organização das Nações Unidas (ONU) criou a Comissão Mundial sobre Meio Ambiente e Desenvolvimento (CMMAD) que debateu e recomendou maneiras de conciliar a preservação ambiental com desenvolvimento econômico. No ano de 1987 com o término do trabalho, a primeiraministra da Noruega Gro Harlen Brundtland apresentou o seguinte conceito sobre desenvolvimento sustentável (ZASSO et al., 2014)

Desenvolvimento Sustentável é o desenvolvimento que busca suprir as necessidades do presente sem comprometer a possibilidade de atendê-las no futuro. As gerações futuras devem ter acesso a, pelo menos, o mesmo nível de capital natural que as gerações que as antecederam. Para que isso seja possível, a proteção do meio ambiente é condição inerente ao desenvolvimento sustentável e objetivo de todo o Planeta, pois o problema ecológico não se esgota no limite geográfico dos países (ZASSO et al., 2014, p. 83). 
Segundo Brito (2017), o Relatório Brundtland recomenda que o mundo inteiro consuma os recursos naturais na mesma proporção que o planeta tem para repor estes recursos naturalmente e faz uma importante observação: Durante muitos anos a sociedade preocupou-se com os efeitos do desenvolvimento sobre o meio ambiente, todavia nos dias de hoje existe a preocupação do desenvolvimento econômico ser impedido ou revertido por conta da degeneração ambiental. Para Pereira (2016), um país que pretende obter ganhos futuros na área econômica e social deve procurar incorporar na cabeça dos cidadãos através de gestos e não somente com o uso de palavras o sentido e a importância do desenvolvimento sustentável que busca a necessidade básica humana e a igualdade social.

Visando implantar a Responsabilidade Socioambiental nas atividades administrativas e operacionais da Administração Pública, o Ministério do Meio Ambiente (MMA) elaborou um programa denominado Agenda A3P, que se fundamenta: no Capítulo IV da Agenda 21, que indica aos países o "estabelecimento de programas voltados ao exame dos padrões insustentáveis de produção e consumo e o desenvolvimento de políticas e estratégias nacionais de estímulo a mudanças nos padrões insustentáveis de consumo"; no Princípio oito da Declaração do Rio/92, que afirma que "os Estados devem reduzir e eliminar padrões insustentáveis de produção e consumo e promover políticas demográficas adequadas" e, na Declaração de Joanesburgo, que institui a "adoção do consumo sustentável como princípio basilar do desenvolvimento sustentável" (LUIZ et al., 2013).

A A3P foi criada em 1999, mas somente dois anos depois foi oficialmente criado o Programa Agenda Ambiental na Administração Pública. No ano de 2002 a A3P recebeu um prêmio pela relevância do trabalho e pela geração de resultados positivos, concedido pela Organização das Nações Unidas para a Educação, a Ciência e a Cultura (UNESCO), na categoria Meio Ambiente como o "Melhor dos Exemplos". Devido a sua importância, a A3P foi incluída no Plano Plurianual (PPA) de (2004/2007) e no PPA (2008/2011) com a finalidade de garantir recursos para a sua implantação e tornando-se uma referência de sustentabilidade nas atividades públicas (MMA, 2020b). 
O Programa A3P que ainda não possuía um normativo legal foi institucionalizado através da Portaria ํo 28 do Ministério do Meio Ambiente, publicada em 20 de fevereiro de 2018 no Diário Oficial da União (DOU) e em 1ํ de março do mesmo ano foram institucionalizadas as diretrizes do programa através da Portaria SAIC № 03.

A Portaria oㅡ 03 de 27 de fevereiro de 2018, com base na Portaria oㅡ 28 do MMA de 20 de fevereiro de 2018 instituiu as diretrizes para o Programa A3P. Em seu Capítulo

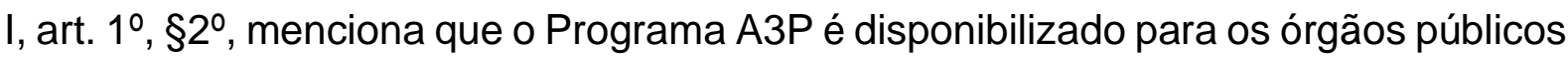
dos três poderes da república: Legislativo; Executivo e Judiciário e para as três instâncias: Federal; Estadual e Municipal e em seu Capítulo II, art. $3^{\circ}$ traz descritos os Objetivos da A3P (BRASIL, 2018). Como objetivos mais relevantes da A3P temos: Sensibilizar e Capacitar os gestores públicos para as questões socioambientais; Estimular o uso racional dos recursos naturais e a redução de gastos institucionais; Colaborar para revisão dos padrões de produção e consumo e para a adoção de novos referenciais de sustentabilidade no âmbito da administração pública; Reduzir o impacto socioambiental negativo direto e indireto ocasionado pela execução das atividades de caráter administrativo e operacional e Contribuir para a melhoria da qualidade de vida.

A A3P busca criar uma cultura de responsabilidade socioambiental na administração pública, por este motivo é estruturada em seis eixos temáticos descritos no Capítulo IV, art. 6º, $\S^{10}$ da Portaria no 03/2018. Os Eixos Temáticos da A3P são: Eixo 1- Uso racional dos recursos naturais e bens públicos; Eixos 2 - Gestão adequada dos resíduos gerados; Eixo 3 - Qualidade de vida no ambiente de trabalho; Eixo 4 Sensibilização e capacitação dos servidores; Eixo 5 - Contratações públicas sustentáveis e Eixo 6 - Construções sustentáveis.

Para as instituições públicas implantarem a A3P é necessária primeiramente a participação no processo de adesão a A3P. Para aderir formalmente é necessário firmar entre os interessados e o MMA um Termo de Adesão. Neste termo a parte interessada se compromete a implantar a $\mathrm{A} 3 \mathrm{P}$ e desenvolver projetos destinados a este fim (MMA, 2017a). Segundo o MMA, o número de Termos de Adesão à A3P 
firmados pelos órgãos públicos pertencentes aos três poderes da república e as três esferas de governo vem aumentando cumulativamente ao longo dos anos. No ano de 2009 havia 58 Termos de Adesão firmados, sendo 26 de órgãos da esfera federal, 20 da esfera estadual e 12 da esfera municipal. Em 2020 o número de Termos de Adesão firmados passou para 490, sendo 179 de órgãos da esfera federal, 153 da esfera estadual e 158 da esfera municipal (MMA, 2020c).

A Cartilha da Agenda A3P descreve a responsabilidade socioambiental como:

um processo contínuo e progressivo de desenvolvimento de competências cidadãs, com a aceitação de responsabilidades sobre questões sociais e ambientais relacionadas a todos os públicos com os quais a entidade interage: trabalhadores, consumidores, governo, empresas, investidores e acionistas, organizações da sociedade civil, mercado e concorrentes, comunidade e o próprio meio ambiente (MMA, 2009).

Cabe ressaltar que uma gestão ambiental eficiente se deve ao engajamento e ao comprometimento de todos os servidores na transformação de hábitos, rotinas, processos e serviços objetivando a sustentabilidade e a melhoria da qualidade de vida no trabalho.

O art. $16^{\circ}$ do decreto 7.746 de 05 de junho de 2012 alterado pelo decreto 9.178 de 23 de outubro de 2017 obriga à Administração Pública Federal direta, autárquica e fundacional e as empresas estatais dependentes a elaborar e implementar PLS, conforme ato editado pela Secretaria de Gestão do Ministério do Planejamento, Desenvolvimento e Gestão. A Instrução Normativa nํ 10, de 12/11/2012, estabelece as regras para elaboração dos PLS de que trata o art. 16을 do decreto ํำ 7.746/2012. $\mathrm{O}$ art. $3^{\circ}$ dessa normativa define o PLS como uma ferramenta de planejamento para os órgãos da Administração Pública estabelecerem suas práticas de sustentabilidade e racionalização de gastos e processos.

Em seus artigos $5^{\circ}, 8^{\circ}$ e $11^{\circ}$ a normativa estabelece o conteúdo mínimo que deve constar em um PLS, os temas referentes às práticas de sustentabilidade e de racionalização de gastos que deverão ser abordados e as iniciativas que podem ser 
usadas pelos órgãos da administração pública federal na elaboração do PLS respectivamente. As iniciativas que poderão ser observadas na criação do PLS são: Programa de Eficiência do Gasto Público (PEG); Programa Nacional de Conservação de Energia Elétrica (PROCEL); Agenda A3P; Coleta Seletiva Solidária (CSS); Projeto Esplanada Sustentável (PES) e Contratações Públicas Sustentáveis (CPS). De acordo com o Parágrafo único do art. 11ํㅡㄹ os Planos de Ação análogos às iniciativas descritas acima, poderão ser incorporados aos PLS dos órgãos ou entidades (BRASIL, 2012). A normativa com o intuito de valorizar os órgãos públicos federais que implementaram a A3P, prevê a A3P como um dos programas referenciais do PLS (MMA, 2020d).

\subsection{SISTEMA DE GESTÃO AMBIENTAL EM IES}

As IES ao longo dos anos têm se esforçado para contribuir com a preservação e com o aumento da harmonia do homem em relação ao meio ambiente. Para Tauchen; Brandli (2006) existem duas linhas de pensamento com relação ao papel das IES no desenvolvimento sustentável. A primeira com relação à qualificação dos alunos, futuros tomadores de decisão, mostrando a importância da preocupação com as questões ambientais em suas práticas profissionais e a segunda a implantação de Sistemas de Gestão Ambiental (SGAs) nos campi das IES como modelos e exemplos de gestão sustentável.

Segundo Moraes et al. (2014) o desenvolvimento sustentável nas organizações surge através do gerenciamento de ações sustentáveis que são conduzidas através de um Sistema de Gestão Ambiental (SGA) que possibilita que suas atividades danifiquem o mínimo possível o meio ambiente e consequentemente não afete a qualidade de vida de seus colaboradores e de toda a comunidade. As empresas prestadoras de serviços e algumas instituições de ensino também devem aderir a esta nova realidade da mesma maneira que as empresas que possuem linhas de produção.

As vantagens das organizações em possuir um SGA são inúmeras e transcende cumprir legislações e ser uma estratégia de marketing. As vantagens atingem os 
setores financeiro, produtivo e social. O SGA visa atingir o tripé da Sustentabilidade que busca o crescimento econômico e social levando em consideração a preocupação ambiental reduzindo os impactos causados pela organização, seja uma pequena empresa, uma multinacional, uma IES ou uma estratégia de políticas de governo (MORAES et al., 2014).

No Brasil, as IES para se tornarem mais sustentáveis utilizam seus campus como laboratórios para práticas sustentáveis. Como exemplo temos a Universidade Federal do Rio de Janeiro (UFRJ) que através de um decreto estadual criou o Fundo Verde de Desenvolvimento e Energia para a Cidade Universitária com o objetivo de investir em projetos de mobilidade, uso de energia eficiente e gerada a partir de fontes alternativas, redução do consumo de água e geração de resíduos, monitoramento de dados e produção de indicadores no campus. Os projetos desenvolvidos com o auxílio do Fundo são: Programas de água; Programas de Energia e Programas de Mobilidade (MARCELINO, 2016).

\section{METODOLOGIA DE PESQUISA}

\subsection{CLASSIFICAÇÃO DA PESQUISA}

Esta pesquisa se caracteriza de natureza aplicada pelo fato de fornecer informações que podem subsidiar eventuais ajustes e melhorias no processo de implementação do PLS no CEFET/RJ visando tornar a instituição mais sustentável. Para Moresi (2003, p. 8) a pesquisa aplicada é aquela que produz conhecimentos com o intuito de ser aplicado para a solução de problemas peculiares. Pela forma de abordagem dos problemas a pesquisa é classificada como qualitativa. Qualitativa por ter a intenção de pesquisar e entender as particularidades do PLS e da adesão à Agenda A3P. A pesquisa possui também características quantitativas, por buscar traduzir em números as informações dos questionários aplicados na pesquisa. Quanto à finalidade, a pesquisa é caracterizada como sendo exploratória por proporcionar uma maior ligação com as questões relacionadas à implantação do PLS e da adoção por parte da 
instituição à Agenda A3P tornando-a mais evidente. O objetivo é aprimorar ideias ou descobrir novas visões sobre as questões apresentadas.

Com relação aos meios de investigação a pesquisa pode ser classificada como pesquisa de campo, pesquisa documental, pesquisa bibliográfica e estudo de caso. É considerada uma pesquisa de campo pelo fato de ser feita no CEFET/RJ e por utilizar vários elementos para realização da investigação sobre a implementação do PLS e da adoção da Agenda A3P na instituição. Estes elementos são: entrevistas e aplicação de questionários.

\subsection{INSTRUMENTOS DE COLETA, ANÁLISE E TRATAMENTO DE DADOS}

Para o avanço desta pesquisa foi feita uma revisão da literatura utilizando-se bases como: Web of Science, Scopus, Biblioteca Digital de Teses e Dissertações (BDTD) da Universidade Federal Fluminense (UFF) e da Universidade Federal de Santa Catarina (UFSC) e o Google Acadêmico. Foram utilizadas para busca na base de dados as seguintes palavras chaves: Sustentabilidade Ambiental, Práticas Ambientais, Instituições de Ensino, Plano de Gestão de Logística Sustentável (PLS), Instituto Federal de Ensino e Agenda Ambiental na Administração Pública (A3P). As Leis, Decretos, Portarias, Instruções Normativas, Resoluções e cartilhas da A3P foram consultadas em sites do governo.

Para atingir o objetivo geral da pesquisa foram utilizados diversos instrumentos de coleta e tratamento de dados. Foi realizada uma investigação para verificar se a instituição segue as ações propostas na Agenda A3P e uma análise da aplicação da legislação ambiental nas atividades do CEFET/RJ.

Para análise da aplicação da legislação ambiental nas atividades da instituição foi realizada uma pesquisa bibliográfica através de legislações, legislações ambientais, cartilhas do MMA, site do CEFET/RJ, Portal CEFET SUSTENTÁVEL e sites do governo acerca da implementação do PLS e da agenda A3P em órgãos públicos 
federais. Em seguida foi feita uma pesquisa documental acerca do conteúdo do PLS publicado pelo CEFET/RJ e dos documentos exigidos pela legislação pertinente. E para finalizar foi feita uma entrevista com o responsável pela elaboração do PLS e pelas atividades socioambientais do CEFET/RJ.

Com relação à análise e tratamento de dados foi efetuada uma análise documental do conteúdo do PLS publicado pela instituição com o exigido pela legislação ambiental vigente e uma entrevista semiestruturada utilizando questões relacionadas às legislações exigidas para implantação do PLS e aderência a Agenda A3P. Foi realizada uma entrevista semiestruturada com o coordenador da Divisão de Estratégia para Sustentabilidade Ambiental Institucional (DISAI) responsável diretamente pela elaboração do PLS e pelas atividades socioambientais nas unidades do CEFET/RJ. A entrevista possui a finalidade de verificar qualitativamente se a instituição está cumprindo o exigido pela legislação.

Para mensurar se a instituição está seguindo as ações propostas na Agenda A3P foi realizada uma pesquisa documental no PLS do CEFET/RJ. Em sequência foi feita uma entrevista com o responsável pela implementação e pelo monitoramento do PLS na instituição. Para finalizar foi enviado ao Chefe da DISAI, aos membros do COSAI (Comitê de Sustentabilidade Ambiental Institucional), aos Gerentes Administrativos, Técnicos Administrativos e Professores envolvidos na implantação das ações da Agenda A3P nas unidades do CEFET/RJ um questionário contendo perguntas sobre a Agenda A3P.

Com relação à análise e tratamento de dados foi feita uma análise documental do PLS com relação às práticas adotadas referentes a cada eixo temático da Agenda A3P. Foi realizada uma entrevista semiestruturada com o servidor da DISAI responsável pela implementação e pelo monitoramento do PLS com questões referentes à aderência do CEFET/RJ a Agenda A3P e as práticas implementadas. Em sequência foi enviado um questionário elaborado e adaptado do modelo de check-list do Artigo "Agenda Ambiental na Administração Pública: Uma análise da aderência de uma IFES as diretrizes propostas pela A3P" Freitas; Borgert e Pfitscher (2011), do questionário 
da Dissertação "Sustentabilidade socioambiental no gerenciamento dos campi da Universidade Federal do Ceará" Vasconcelos (2015) e de uma cartilha do MMA "Gestão socioambiental em escolas" MMA (2017b), contendo perguntas relacionadas aos principais objetivos e aos eixos temáticos da Agenda A3P ao Chefe da DISAI unidade Maracanã, aos membros do COSAl, aos Gerentes Administrativos das sete unidades restantes da instituição: Angra dos Reis; Nova Friburgo; Itaguaí; Petrópolis; Valença; Nova Iguaçu e Maria da Graça e aos Técnicos Administrativos e Professores envolvidos na implantação das ações da Agenda A3P nas unidades do CEFET/RJ. Finalmente foi realizada uma análise qualitativa e quantitativa destes questionários com a finalidade de mensurar, através da percepção dos servidores, se as unidades do CEFET/RJ estão seguindo as ações propostas pela Agenda A3P. A Análise, o processamento e a interpretação dos dados foram realizados através do software Microsoft Excel 2007. Os dados numéricos foram adquiridos através da utilização de ferramentas da Matemática Simples como: Porcentagem, gráficos e tabelas.

O questionário foi elaborado com 80 perguntas objetivas distribuídas em três partes. A primeira parte contém perguntas sobre os principais objetivos da Agenda A3P com a finalidade de verificar a adesão da instituição aos objetivos, utilizando como opção de resposta uma Escala Likert de cinco pontos: Concordo Totalmente (CT); Concordo Parcialmente (CP); Não Concordo, Não Discordo (NC/ND); Discordo Parcialmente (DP) e Discordo Totalmente (DT). A segunda parte do questionário é composta por perguntas utilizando como opção de resposta "Sim" ou "Não", distribuídas em grupos referentes aos seis Eixos Temáticos da Agenda A3P, com o intuito de verificar a adesão da instituição aos Eixos Temáticos. A terceira parte do questionário contém duas perguntas objetivas que possuem a finalidade de verificar a percepção dos servidores com relação aos três maiores incentivos e obstáculos à implantação das ações de Responsabilidade Socioambiental no CEFET/RJ.

Os questionários foram enviados para 65 servidores Técnicos Administrativos e Professores distribuídos pelas oito unidades da instituição, por e-mail no período de outubro de 2020 a novembro de 2020. Entre os servidores Técnicos Administrativos há alguns que são Membros do COSAI, Gerentes Administrativos de unidades, da 
Prefeitura e da subprefeitura de alguma unidade. Entre os Professores há alguns que também são Membros do COSAI. Responderam ao questionário 15 servidores, que corresponde a $23,08 \%$ do total, sendo 11 técnicos administrativos e 4 professores.

Os questionários respondidos pelos servidores participantes da pesquisa estão distribuídos pelas unidades do CEFET/RJ da seguinte forma: Maracanã (6); Maria da Graça (3); Petrópolis (2); Nova Friburgo (1); Valença (1); Angra dos Reis (1) e Nova Iguaçu (1). Devido ao fato dos servidores do CEFET/RJ (campus Itaguaí) não terem respondido aos questionários que receberam por e-mail, tornou-se impossível medir a percepção dos servidores da unidade em relação às ações da Agenda A3P implantadas na instituição.

A análise dos dados coletados através dos instrumentos descritos e da utilização das ferramentas descritas acima para o tratamento dos dados, fornecerá informações necessárias para subsidiar eventuais ajustes e melhorias a serem realizadas no processo de implementação do PLS e na adoção das ações correspondentes aos eixos temáticos da Agenda A3P, resultando em uma instituição mais sustentável e bem mais ajustada com a Agenda A3P no futuro.

\section{RESULTADOS DA PESQUISA}

\subsection{O CEFET/RJ}

Os Centros Federais de Educação Tecnológica representam uma importante evolução nas instituições educacionais que acompanharam e ajudaram a desenvolver o processo de industrialização no país no século XX. O CEFET/RJ teve a sua origem em 1917, como Escola Normal de Artes e Ofícios Wenceslau Brás. A partir da Lei no 6.545, de 30 de junho de 1978 se transformou em uma instituição autárquica de regime especial vinculada ao Ministério da Educação (MEC) (CEFET/RJ, 2020a).

O CEFET/RJ possui como diretrizes estratégicas a missão de propiciar a educação através da tríade ensino, pesquisa e extensão resultando de modo reflexivo e crítico, na formação de profissionais que sejam capazes de contribuir para o desenvolvimento 
científico, cultural, tecnológico e econômico da sociedade e como visão, pretende tornar-se uma Universidade Federal de Ciências Aplicadas do Rio de Janeiro, incorporando os seguintes valores: Integração; Responsabilidade; Comprometimento sustentável; Busca pela excelência; Autonomia; Ética e transparência; Respeito (humano e à diversidade); Compartilhamento de ações e decisões; Meritocracia. A instituição possui um campus-sede Maracanã e mais sete campi espalhados pelo estado do Rio de Janeiro, que são: Angra dos Reis, Itaguaí, Maria da Graça, Nova Friburgo, Nova Iguaçu, Petrópolis e Valença (CEFET/RJ, 2018a).

Com a finalidade de atender a legislação vigente e de disseminar a importância de se adotar práticas sustentáveis na instituição, em outubro de 2017 o CEFET/RJ criou a DISAI, vinculada à Diretoria de Gestão Estratégica (DIGES). O principal objetivo da DISAI é o de transformar ideias em ações referentes à gestão e educação ambiental, que envolva aspectos científicos, legais, ecológicos, econômicos, políticos, culturais e éticos, resultando em uma maior percepção socioambiental por parte de todos os indivíduos pertencentes à comunidade. Entre as inúmeras competências da DISAI estão a de organizar a estrutura de implantação da Agenda A3P no CEFET/RJ, orientar a sua implantação e a de coordenar a elaboração do PLS da instituição (CEFET SUSTENTÁVEL, 2020a).

Através da Portaria № 1463, de 26 de dezembro de 2017 foi criado o COSAl que funciona como um órgão colegiado de natureza consultiva e propositiva, de caráter permanente, que possui a finalidade de colaborar com a DISAI nas políticas e ações do CEFET/RJ na área de sustentabilidade institucional. É composta por dez servidores representantes das seguintes diretorias sistêmicas distribuídas pelas unidades da instituição: DIPPG- Diretoria de Pesquisa e Pós-graduação; DIREXDiretoria de Extensão; DIGES; DIRAP- Diretoria de Administração e Planejamento e DIREN- Diretoria de Ensino. Para dar continuidade aos propósitos da implantação das práticas sustentáveis nas atividades da instituição, o CEFET/RJ aderiu formalmente à Agenda A3P no dia 26 de janeiro de 2018. Em 14 de setembro de 2018, o Conselho Diretor da instituição, aprovou e publicou a Resolução no 44 que trata da Política de Sustentabilidade Ambiental do CEFET/RJ. Esta política busca promover uma gestão 
ambiental integrada, adotando padrões sustentáveis de produção e consumo e estimulando ações de Educação Ambiental. Este documento foi norteador para a elaboração do PLS. O PLS foi aprovado e publicado pelo Conselho Diretor, através da Resolução ํㅜ 56 de 23 de novembro de 2018 (CEFET SUSTENTÁVEL, 2020a).

\subsection{ANÁLISE DOS DADOS}

Os dados coletados através dos questionários foram separados, agrupados levandose em consideração as partes correspondentes do questionário, os eixos temáticos da A3P e os tipos de resposta. Em seguida foram consolidados em Planilhas do Excel para uma melhor análise dos dados.

\subsubsection{ANÁLISE DOS PRINCIPAIS OBJETIVOS DA A3P}

Na Figura 1 é mostrado o resultado coletado através da aplicação do questionário da pesquisa com relação à Parte 1 que visa verificar a adesão da instituição aos objetivos principais da A3P. 
Figura 1 - Principais objetivos da A3P - Resultados da pesquisa

Parte 1 - Principais objetivos da A3P

Objetivo 1 -Sensibilização de Gestores.

\begin{tabular}{|c|c|c|c|c|c|}
\hline Perguntas & $\begin{array}{c}\text { CT } \\
\text { (Quant. - \%) }\end{array}$ & $\begin{array}{c}\text { CP } \\
\text { (Quant. - \%) }\end{array}$ & $\begin{array}{c}\text { NC/ND } \\
\text { (Quant. - \%) }\end{array}$ & $\begin{array}{c}\text { DP } \\
\text { (Quant. - \%) } \\
\end{array}$ & $\begin{array}{c}\text { DT } \\
\text { (Quant. - \%) }\end{array}$ \\
\hline $\begin{array}{l}\text { A Gestão ambiental do CEFET/RJ promove a } \\
\text { sensibilização de seus gestores com relação à } \\
\text { importância das questões socioambientais? }\end{array}$ & $3-20 \%$ & $7-46 \%$ & $4-27 \%$ & $1-7 \%$ & \\
\hline \multicolumn{6}{|c|}{ Objetivo 2 - Economia de Recursos Naturais e redução de gastos institucionais. } \\
\hline $\begin{array}{l}\text { A Gestão ambiental do CEFET/RJ promove o uso } \\
\text { coerente dos recursos naturais e dos bens } \\
\text { públicos? }\end{array}$ & $3-20 \%$ & $7-46 \%$ & $4-27 \%$ & $1-7 \%$ & \\
\hline \multicolumn{6}{|c|}{ Objetivo 3 - Redução do impacto socioambiental negativo. } \\
\hline $\begin{array}{l}\text { A Gestão ambiental do CEFET/RJ tem adotado } \\
\text { medidas que reduzem os impactos negativos } \\
\text { diretos e indiretos na execução de suas atividades } \\
\text { administrativas e operacionais? }\end{array}$ & $2-13 \%$ & $5-33 \%$ & $7-47 \%$ & & $1-7 \%$ \\
\hline \multicolumn{6}{|c|}{ Objetivo 4 - Revisão dos padrões de produção e consumo e a adoção de novos referenciais de sustentabilidade. } \\
\hline $\begin{array}{l}\text { A Gestão ambiental do CEFET/RJ tem apoiado na } \\
\text { revisão dos seus padrões de produção e } \\
\text { consumo? }\end{array}$ & $3-20 \%$ & $4-27 \%$ & $6-40 \%$ & $1-6 \%$ & $1-7 \%$ \\
\hline $\begin{array}{l}\text { A Gestão ambiental do CEFET/RJ tem } \\
\text { colaborado na adoção de novos referenciais de } \\
\text { sustentabilidade? }\end{array}$ & $4-27 \%$ & $4-27 \%$ & $5-33 \%$ & & $2-13 \%$ \\
\hline \multicolumn{6}{|l|}{ Objetivo 5 -Melhoria da qualidade de vida. } \\
\hline $\begin{array}{l}\text { A Gestão Ambiental do CEFET/RJ colabora com } \\
\text { a melhoria da qualidade de vida dos docentes, } \\
\text { alunos. técnicos administrativos e terceirizados? }\end{array}$ & $1-7 \%$ & $5-33 \%$ & $7-47 \%$ & $2-13 \%$ & \\
\hline
\end{tabular}

Fonte: Adaptado de Freitas et al. (2011).

A partir da análise da Figura 1 foi possível inferir que a maioria dos servidores respondentes da pesquisa concorda totalmente e parcialmente que a Gestão ambiental da instituição fomenta a sensibilização dos gestores, proporciona o uso adequado dos recursos naturais e dos bens públicos e colabora com a adoção de novos referenciais de sustentabilidade. Com relação às perguntas do objetivo 3 que trata sobre a adoção por parte da Gestão ambiental da instituição por medidas que reduzam os impactos negativos diretos e indiretos na execução de suas atividades administrativas e operacionais, a pergunta 1 do objetivo 4 que diz respeito ao apoio dado pela Gestão ambiental na revisão dos seus padrões de produção e consumo e

Disponível em: https://www.nucleodoconhecimento.com.br/engenharia-de-producao/logistica- 
a pergunta do objetivo 5 que se refere à colaboração por parte da Gestão ambiental com a melhoria da qualidade de vida dos docentes, alunos, técnicos administrativos e terceirizados, as respostas dos servidores ficaram divididas entre os servidores que não concordam e não discordam e os servidores que concordam parcialmente e totalmente. Ao analisar a aplicação da legislação ambiental nas atividades socioambientais do CEFET/RJ foram observadas algumas ações realizadas pela Gestão ambiental da instituição no sentido de reduzir os impactos Socioambientais negativos diretos e indiretos na execução de suas atividades; Reformular seus padrões de consumo e de melhorar a qualidade de vida dos docentes, alunos, técnicos administrativos e terceirizados como: Coleta Seletiva Solidária, coleta de pilhas e baterias de celular, projetos de consumo consciente de água e energia, palestras sobre promoção da saúde, eventos culturais, campanhas de vacinação e palestras e cursos de sensibilização e capacitação. Dessa forma, a análise realizada da percepção dos respondentes a essas perguntas sugere a falta de conhecimento sobre algumas ações implantadas na instituição pela Gestão Ambiental, indicando a necessidade de melhorias no processo de divulgação dessas ações.

\subsubsection{ANÁLISE DOS EIXOS TEMÁTICOS DA A3P}

Para análise das perguntas voltadas para a instituição referente à Parte 2 do questionário que visam verificar a adesão da instituição aos Eixos Temáticos da A3P foram elaboradas tabelas com os resultados mostrando a aderência da instituição a cada eixo temático.

\subsubsection{ANÁLISE DO EIXO 1 - USO RACIONAL DOS RECURSOS NATURAIS E BENS PÚBLICOS}

Nas Figuras 2 e 3 são mostrados os resultados da pesquisa referentes às perguntas do Eixo 1 da A3P e a aderência da instituição ao eixo. 
Figura 2 - Eixo 1 da A3P - Resultados da pesquisa

Parte 2 - Eixos temáticos da A3P.

Eixo 1 - Uso racional dos recursos naturais e bens públicos.

Grupo 1 - Uso Racional de Água.

\begin{tabular}{|c|c|c|c|}
\hline Perguntas & $\begin{array}{c}\text { SIM } \\
\text { (Quant. - \%) }\end{array}$ & $\begin{array}{c}\text { NÃ O } \\
\text { (Quant. - \%) }\end{array}$ & $\begin{array}{c}\text { NÃO } \\
\text { RESPONDIDO }\end{array}$ \\
\hline $\begin{array}{l}\text { O CEFET/RJ realiza algum procedimento de } \\
\text { monitoramento/ redução no consumo de } \\
\text { água? }\end{array}$ & $7-46 \%$ & $7-47 \%$ & $1-7 \%$ \\
\hline $\begin{array}{l}\text { O CEFET/RJ desenvolve campanhas de uso } \\
\text { racional da água? }\end{array}$ & $9-60 \%$ & $5-33 \%$ & $1-7 \%$ \\
\hline \multicolumn{4}{|l|}{ Grupo 2 - Uso Racional de Energia. } \\
\hline $\begin{array}{l}\text { O CEFET/RJ realiza algum procedimento de } \\
\text { monitoramento/redução no consumo de } \\
\text { energia? }\end{array}$ & $7-46 \%$ & $7-47 \%$ & $1-7 \%$ \\
\hline $\begin{array}{l}\text { O CEFET/RJ desenvolve programa de } \\
\text { eficiência energética? }\end{array}$ & $2-13 \%$ & $12-80 \%$ & $1-7 \%$ \\
\hline $\begin{array}{l}\text { No CEFET/RJ há fontes alternativas de } \\
\text { energia? }\end{array}$ & $1-7 \%$ & $12-80 \%$ & $2-13 \%$ \\
\hline \multicolumn{4}{|l|}{ Grupo 3 - Uso Racional de Papel. } \\
\hline $\begin{array}{l}\text { O CEFET/RJ realiza algum procedimento de } \\
\text { monitoramento/redução no consumo de } \\
\text { papel? }\end{array}$ & $9-60 \%$ & $6-40 \%$ & \\
\hline $\begin{array}{l}\text { No CEFET/RJ existe preferência ao uso de } \\
\text { documentos digitalizados e mensagens } \\
\text { eletrônicas ( } e \text {-mail) na comunicação e atos } \\
\text { de expediente? }\end{array}$ & $11-73 \%$ & $4-27 \%$ & \\
\hline
\end{tabular}

Fonte: Adaptado de Freitas et al.,(2011), Vasconcelos (2015) e MMA (2017) 
Figura 3 - Eixo 1 da A3P - Resultados da pesquisa (conclusão)

Parte 2 - Eixos temáticos da A3P.

Eixo 1 - Uso racional dos recursos naturais e bens públicos.

Grupo 1 - Uso Racional de Água.

\begin{tabular}{|c|c|c|c|}
\hline Perguntas & $\begin{array}{c}\text { SIM } \\
\text { (Quant. - \%) }\end{array}$ & $\begin{array}{c}\text { NÃ̃ } \\
\text { (Quant. - \%) }\end{array}$ & $\begin{array}{c}\text { NÃO } \\
\text { RESPONDIDO }\end{array}$ \\
\hline \multicolumn{4}{|l|}{ Grupo 3 - Uso Racional de Papel. } \\
\hline $\begin{array}{l}\text { Todas as impressoras dos setores do } \\
\text { CEFET/RJ estão programadas para imprimir } \\
\text { frente e verso? }\end{array}$ & $5-33 \%$ & $10-67 \%$ & \\
\hline \multicolumn{4}{|c|}{ Grupo 4 - Uso Racional de Combustiveis, Copos Plásticos e outros. } \\
\hline $\begin{array}{l}\text { O CEFET/RJ realiza algum procedimento de } \\
\text { monitoramento/redução no consumo de } \\
\text { copos de plástico (descartáveis)? }\end{array}$ & $7-47 \%$ & $8-53 \%$ & \\
\hline $\begin{array}{l}\text { O CEFET/RJ realiza algum procedimento de } \\
\text { monitoramento/redução no consumo de } \\
\text { combustiveis em sua frota de veiculos? }\end{array}$ & $4-27 \%$ & $10-67 \%$ & $1-6 \%$ \\
\hline $\begin{array}{l}\text { O CEFET/RJ disponibiliza copos e xicaras } \\
\text { feitos de material permanente, como vidro e } \\
\text { porcelana, para todos os servidores? }\end{array}$ & $3-20 \%$ & $12-80 \%$ & \\
\hline $\begin{array}{l}\text { O CEFET/RJ realiza campanhas de } \\
\text { sensibilização de uso racional de materiais de } \\
\text { consumo? }\end{array}$ & $6-40 \%$ & $9-60 \%$ & \\
\hline $\begin{array}{l}\text { O CEFET/RJ realiza algum procedimento de } \\
\text { monitoramento/redução no consumo de } \\
\text { outros tipos de materiais/recursos que } \\
\text { possam ocasionar impactos ambientais } \\
\text { significativos? }\end{array}$ & $5-33 \%$ & $10-67 \%$ & \\
\hline $\begin{array}{l}\text { O CEFET/RJ possui algum servidor } \\
\text { responsável pelo monitoramento do consumo } \\
\text { dos recursos naturais e dos bens públicos? }\end{array}$ & $5-33 \%$ & $7-47 \%$ & $3-20 \%$ \\
\hline Aderência ao Eixo 1 & $81-\mathbf{3 8} \%$ & $119-57 \%$ & $10-5 \%$ \\
\hline
\end{tabular}

Fonte: Adaptado de Freitas et al.,(2011), Vasconcelos (2015) e MMA (2017)

A partir da análise das Figuras 2 e 3, a aderência da instituição ao Eixo 1 (Uso Racional dos Recursos Naturais e Bens Públicos) da A3P é parcial e corresponde a $38 \%$ de todo o eixo. Para maioria dos participantes da pesquisa, o CEFET/RJ realiza campanhas de uso racional de água, mas não realiza para sensibilização a respeito do uso racional de materiais de consumo. Com relação ao monitoramento e a redução do consumo, a maioria dos servidores consideram que a instituição executa para papel, 47\% consideram que não executa para água e energia, 53\% consideram que não realiza para copos plásticos descartáveis e para combustíveis utilizados na frota

Disponível em: https://www.nucleodoconhecimento.com.br/engenharia-de-producao/logistica- 
de veículos e outros tipos de materiais e recursos que causam impactos ambientais significativos a maioria considera que não. Para a maioria dos respondentes, a instituição dá preferência ao uso de documentos digitalizados e mensagens eletrônicas (e-mail) e consideram que todas as impressoras da instituição não estão configuradas para imprimir frente e verso. Para a maioria dos servidores a instituição não desenvolve programas e projetos de eficiência energética, não possui fontes alternativas de energia e não disponibiliza copos e xícaras de material permanente. Para 47\%, o CEFET/RJ não possui nenhum servidor responsável pelo monitoramento do consumo de recursos naturais e bens públicos.

Ao analisar a aplicação da legislação ambiental nas atividades socioambientais do CEFET/RJ é verificado que a instituição observou as diretrizes da Lei no 9.433/1997 que instituiu a Política Nacional dos Recursos Hídricos e o Decreto ํㅜㄴ.131/2002 que dispõe sobre medidas emergenciais de redução do consumo de energia elétrica no âmbito da Administração Pública Federal. Foi apurado que o CEFET/RJ (campus Maracanã) realiza o monitoramento e reduz o consumo de água/esgoto no campus através de várias ações como: Aplicação de Checklist em busca de desperdício ou vazamento de água em banheiros, torneiras de lavagem de piso interna e externa e chuveiros; Implantação de Sistema de Comunicação Direta sobre vazamento de água através de cartazes fixados nos banheiros com $Q R$ Code e instalação de um Coletor de Águas Pluviais. Com relação ao monitoramento e a redução do consumo de energia são realizadas várias ações no campus como: Verificação dos gastos com a energia elétrica através do monitoramento das contas observando se a demanda contratada condiz com a demanda medida; Mapeamento dos aparelhos elétricos que consomem mais energia com a finalidade de substituí-los por aparelhos mais eficientes e econômicos com o Selo PROCEL e Limpeza dos filtros dos aparelhos de ar-condicionado. Foi instalado no bosque do CEFET/RJ (campus Maracanã) um carregador comunitário de telefones celulares aproveitando a energia solar e em 2018, - CEFET/RJ (campus Maracanã) foi contemplado com um Projeto de Eficiência Energética e Sustentabilidade que prevê a instalação de uma usina solar fotovoltaica com potência de $421,20 \mathrm{kWp}$. 
No Relatório de Sustentabilidade do CEFET/RJ 2020, foi evidenciado, que o CEFET/RJ (campus Maracanã) realiza o monitoramento e redução do consumo de papel (A4) e de combustíveis em toda a sua frota de veículos e não realiza com os copos plásticos (descartáveis) pelo motivo da instituição não os comprar para seus servidores.

\subsubsection{ANÁLISE DO EIXO 2 - GESTÃO ADEQUADA DOS RESÍDUOS SÓLIDOS}

Na Figura 4 são mostrados os resultados da pesquisa referentes às perguntas do Eixo 2 da A3P e a aderência da instituição ao eixo. 
Figura 4 - Eixo 2 da A3P - Resultados da pesquisa

Parte 2 - Eixos temáticos da A3P.

Eixo 2 - Gestão adequada dos residuos sólidos.

Grupo 1 - Política Nacional de Residuos Sólidos.

\begin{tabular}{|c|c|c|c|}
\hline Perguntas & $\begin{array}{c}\text { SIM } \\
\text { (Ouant. - \%) }\end{array}$ & $\begin{array}{c}\text { NÃO } \\
\text { (Ouant. - \%) }\end{array}$ & \begin{tabular}{|c|} 
NÃO \\
RESPONDIDO
\end{tabular} \\
\hline $\begin{array}{l}\text { O CEFET/RJ pratica e incentiva a politica } \\
\text { dos } 5 R^{\prime} \text { 's? (Repensar, Recusar, Reduzir, } \\
\text { Reutilizar e Reciclar). }\end{array}$ & $6-40 \%$ & $9-60 \%$ & \\
\hline $\begin{array}{l}\text { O CEFET/RJ realiza a compostagem de } \\
\text { residuos orgânicos? (Transformação dos } \\
\text { residuos orgânicos em adubo orgânico). }\end{array}$ & $2-13 \%$ & $12-80 \%$ & $1-7 \%$ \\
\hline $\begin{array}{l}\text { Existe levantamento do volume de residuos } \\
\text { gerados no CEFET/RJ? }\end{array}$ & $5-33 \%$ & $9-60 \%$ & $1-7 \%$ \\
\hline $\begin{array}{l}\text { Existe inventário dos residuos gerados nos } \\
\text { laboratórios do CEFET/RJ? }\end{array}$ & $4-27 \%$ & $10-67 \%$ & $1-6 \%$ \\
\hline $\begin{array}{l}\text { O CEFET/RJ possui depósito para } \\
\text { armazenagem dos diferentes tipos de residuos } \\
\text { coletados enquanto aguardam a destinação } \\
\text { final? }\end{array}$ & $5-33 \%$ & $9-60 \%$ & $1-7 \%$ \\
\hline $\begin{array}{l}\text { Existem coleta e destinação sustentável de } \\
\text { óleo inservivel, utilizado no CEFET/RJ? }\end{array}$ & $4-27 \%$ & $10-67 \%$ & $1-6 \%$ \\
\hline $\begin{array}{l}\text { O CEFET/RJ faz a destinação sustentável de } \\
\text { artigos e materiais médico hospitalares } \\
\text { descartados (termômetros, radioativos)? }\end{array}$ & $5-34 \%$ & $8-53 \%$ & $2-13 \%$ \\
\hline $\begin{array}{l}\text { No CEFET/RJ existe processo definido, com } \\
\text { horários e dias, de coleta dos residuos junto } \\
\text { aos setores? }\end{array}$ & $2-14 \%$ & $11-73 \%$ & $2-13 \%$ \\
\hline \multicolumn{4}{|l|}{ Grupo 2 -Coleta Seletiva Solidária. } \\
\hline $\begin{array}{l}\text { O CEFET/RJ possui uma Comissão de } \\
\text { Coleta Seletiva Solidária nos termos do } \\
\text { Decreto } n^{\circ} 5.940 / 2006 ?\end{array}$ & $12-80 \%$ & $2-13 \%$ & $1-7 \%$ \\
\hline $\begin{array}{l}\text { O CEFET/RJ ao realizar a Coleta Seletiva } \\
\text { Solidária segue os termos do Decreto } n^{\circ} \\
5.940 / 2006 ? \text { (Efetuar a separação dos } \\
\text { residuos na fonte e doar para cooperativas e } \\
\text { associações de catadores). }\end{array}$ & $7-50 \%$ & $6-43 \%$ & $1-7 \%$ \\
\hline $\begin{array}{l}\text { O CEFET/RJ ao realizar a Coleta Seletiva } \\
\text { segue a Resolução CONAMA n }{ }^{\circ} 275 \text { de } \\
25 / 04 / 2001 \text { ou a Resolução CONEMA n } \\
55 \text { de } 13 / 12 / 2013 \text { ? (utilização do padrão de } \\
\text { cores para as coletas seletivas). }\end{array}$ & $8-54 \%$ & $5-33 \%$ & $2-13 \%$ \\
\hline Aderência ao Eixo 2 & $60-37 \%$ & $91-55 \%$ & $13-8 \%$ \\
\hline
\end{tabular}

Fonte: Adaptado de Freitas et al.,(2011), Vasconcelos (2015) e MMA (2017)

A partir da análise da Figura 4, a aderência da instituição ao Eixo 2 (Gestão Adequada dos Resíduos Sólidos) da A3P é parcial e corresponde a 37\% de todo o eixo. A maioria dos respondentes da pesquisa considera que o CEFET/RJ, no que se refere aos resíduos sólidos gerados, não realiza o levantamento do volume, não efetua o

Disponível em: https://www.nucleodoconhecimento.com.br/engenharia-de-producao/logistica- 
inventário dos resíduos dos laboratórios, não possui depósito para armazenagem dos diferentes tipos de resíduos coletados, não coleta e realiza a destinação saudável do óleo inservível utilizado, não realiza a destinação correta e sustentável dos artigos e materiais médico hospitalares, não realiza compostagem de resíduos orgânicos e não possui um processo definido com horários e coleta de resíduos junto aos setores da instituição. Para a maioria dos servidores a instituição não prática e não incentiva a política dos 5R's (Repensar, Recusar, Reduzir, Reutilizar e Reciclar). No que concerne a Coleta Seletiva Solidária, a maioria dos servidores considera que o CEFET/RJ possui uma Comissão de Coleta Seletiva Solidária (CCSS) conforme Decreto no 5.940/2006 e utiliza o padrão de cores, exigidos pela legislação, na realização das coletas seletivas. Para $50 \%$ dos servidores, a instituição ao realizar a coleta seletiva efetua a separação dos resíduos na fonte e doa para cooperativas e associações de catadores.

Ao analisar a aplicação da legislação ambiental nas atividades socioambientais do CEFET/RJ foi verificado que a instituição observou as orientações da Lei no 12.305/2010 que instituiu a Política Nacional dos Resíduos Sólidos juntamente com o Decreto 5.940/2006 que estabelece a Separação dos Resíduos Recicláveis e a sua destinação para associações e cooperativas de catadores de materiais recicláveis e a Comissão de Coleta Seletiva Solidária. São evidenciadas diversas ações realizadas pelo CEFET/RJ incentivando a política dos 5R's como: Coleta Seletiva Solidária, coleta de resíduos eletroeletrônicos e mutirões sustentáveis. Realiza o levantamento dos resíduos gerados nos laboratórios e efetua o seu encaminhamento para empresas especializadas no tratamento de resíduos químicos e executa o levantamento do volume de resíduos gerados. Ficaram identificadas também, através da entrevista realizada com a Chefe do DISAI, que o CEFET/RJ (campus Maracanã) e o CEFET/RJ (campus Petrópolis) são as únicas unidades nas quais as cooperativas realizam a retirada dos resíduos recicláveis e o CEFET/RJ (campus Maracanã) é a única unidade que realiza a coleta e a destinação sustentável do óleo de cozinha utilizados pela instituição e trazidos também pela comunidade local. A respeito do lixo orgânico, a 
Chefe da DISAI, explicou que cada campus contrata através de licitação uma empresa para fazer a retirada do lixo orgânico.

\subsubsection{ANÁLISE DO EIXO 3 - QUALIDADE DE VIDA NO AMBIENTE DE TRABALHO}

Nas Figuras 5 e 6 são mostrados os resultados da pesquisa referentes às perguntas do Eixo 3 da A3P e a aderência da instituição ao eixo.

Figura 5 - Eixo 3 da A3P - Resultados da pesquisa

\begin{tabular}{|c|c|c|c|}
\hline \multicolumn{4}{|c|}{ Eixo 3 - Qualidade de vida no ambiente de trabalho. } \\
\hline \multicolumn{4}{|c|}{ Grupo 1 - Uso e Desenvolvimento de Capacidades. } \\
\hline Perguntas & $\begin{array}{c}\text { SIM } \\
\text { (Quant. - \%) }\end{array}$ & 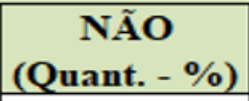 & $\begin{array}{c}\text { NÃO } \\
\text { RESPONDIDO } \\
\end{array}$ \\
\hline $\begin{array}{l}\text { O CEFET/RJ estimula a capacitação dos } \\
\text { seus servidores através do aproveitamento de } \\
\text { suas habilidades individuais e coletivas? }\end{array}$ & $8-53 \%$ & $7-47 \%$ & \\
\hline $\begin{array}{l}\text { O CEFET/RJ estimula a capacitação dos } \\
\text { seus servidores através da autonomia nas } \\
\text { atividades a serem desenvolvidas? }\end{array}$ & $12-80 \%$ & $3-20 \%$ & \\
\hline
\end{tabular}

Fonte: Adaptado de Freitas et al.,(2011), Vasconcelos (2015) e MMA (2017) 
Figura 6 - Eixo 3 da A3P - Resultados da pesquisa (conclusão)

Parte 2 - Eixos temáticos da A3P.

Eixo 3 - Qualidade de vida no ambiente de trabalho.

Grupo 1 - Uso e Desenvolvimento de Capacidades.

\begin{tabular}{l|c|c|c} 
Perguntas & $\begin{array}{c}\text { SIM } \\
\text { (Quant. - \%) }\end{array}$ & $\begin{array}{c}\text { NÃO } \\
\text { (Quant. - \%) }\end{array}$ & $\begin{array}{c}\text { NẼ̃ } \\
\text { RESPNDIDO }\end{array}$ \\
\hline $\begin{array}{l}\text { O CEFET/RJ estimula a capacitação dos } \\
\text { seus servidores através da percepção do } \\
\text { significado do trabalho individual e coletivo? }\end{array}$ & $9-60 \%$ & $6-40 \%$ & - \\
\hline
\end{tabular}

Grupo 2 - Integração Social Interna e Externa.

$\mathrm{O}$ CEFET/RJ incentiva e propicia uma integração social interna e externa com ausência de preconceitos?

$\mathrm{O}$ CEFET/RJ incentiva e propicia à integração social interna através de áreas comuns destinadas a integração de servidores?

O CEFET/RJ incentiva e promove a integração social interna propiciando os relacionamentos interpessoais?

O CEFET/RJ incentiva e promove a integração social interna por meio do senso comunitário?

Grupo 3 - Respeito à Legislação.

O CEFET/RJ respeita e estimula a liberdade de expressão?

O CEFET/RJ respeita e estimula a privacidade pessoal?

O CEFET/RJ respeita e estimula o tratamento imparcial?

Grupo 4 - Condições de Segurança e Saúde no Trabalho.

O CEFET/RJ possui Comissão Interna de Prevenção de Acidentes - CIPA?

O CEFET/RJ possui controle de jornada de trabalho?

O CEFET/RJ se preocupa com a ergonomia dos equipamentos e mobiliários utilizados pelos servidores e estagiários?

O CEFET/RJ oferece aos servidores $e$ estagiários atividades de ginástica laboral e outras atividades semelhantes?

As instalações do CEFET/RJ atende a todas as exigências de acesso para os portadores de deficiência fisica?

O CEFET/RJ possui programa de orientação nutricional?

Os ambientes, especialmente os de trabalho, do CEFET/RJ são salubres?

O CEFET/RJ possui programa de saúde ocupacional?

O CEFET/RJ possui bicicletário?

Aderência ao Eixo 3

\begin{tabular}{|c|c|c}
\hline $3-20 \%$ & $11-73 \%$ & $1-7 \%$ \\
\hline $7-47 \%$ & $8-53 \%$ & - \\
\hline $2-13 \%$ & $13-87 \%$ & \\
\hline $3-20 \%$ & $12-80 \%$ & \\
\hline $9-60 \%$ & $6-40 \%$ & - \\
\hline $8-53 \%$ & $6-40 \%$ & $1-7 \%$ \\
\hline $3-20 \%$ & $11-73 \%$ & $1-7 \%$ \\
\hline $8-53 \%$ & $7-47 \%$ & \\
\hline $166-58 \%$ & $116-41 \%$ & $3-1 \%$ \\
\hline
\end{tabular}

Fonte: Adaptado de Freitas et al.,(2011), Vasconcelos (2015) e MMA (2017)

Disponível em: https://www.nucleodoconhecimento.com.br/engenharia-de-producao/logistica- 
Considerando as informações contidas nas Figuras 5 e 6, a aderência da instituição ao Eixo 3 (Qualidade de Vida no Ambiente de Trabalho) da A3P é parcial e corresponde a $58 \%$ de todo o eixo. No que concerne ao uso e desenvolvimento de capacidades, $53 \%$ dos respondentes da pesquisa consideram que o CEFET/RJ estimula à capacitação aproveitando as capacidades individuais e coletivas dos servidores. Para a maioria dos servidores a instituição fomenta a capacitação através da percepção do significado do trabalho individual e coletivo e da autonomia nas atividades a serem desempenhadas. Com relação à integração social interna e externa, a maioria dos servidores respondentes considera que a instituição incentiva e propicia uma integração social sem preconceitos e promove uma integração social interna em áreas comuns específicas e incentivando os relacionamentos interpessoais. Para 53\% dos servidores o CEFET/RJ incentiva a integração social interna através do senso comunitário. No que se refere ao cumprimento da legislação por parte do CEFET/RJ, a maioria dos servidores considera que a instituição respeita e estimula a liberdade de expressão, a privacidade pessoal e o tratamento imparcial. A respeito das condições de segurança e saúde no trabalho a maioria dos servidores considera que a instituição possui controle de jornada de trabalho e programa de orientação nutricional. Também consideram que o CEFET/RJ não possui uma Comissão Interna de Prevenção de Acidentes (CIPA) e um programa de saúde ocupacional, não oferece aos servidores e estagiários atividades de ginástica laboral e atividades semelhantes e as instalações da instituição não atendem a todas as exigências de acesso para os portadores de deficiência física. Para 53\% dos servidores a instituição não possui bicicletário, os ambientes, principalmente os de trabalho, são salubres e não há por parte do CEFET/RJ uma preocupação com a ergonomia dos equipamentos e mobiliários utilizados pelos servidores e estagiários.

Foram evidenciadas diversas ações, atividades e eventos realizados nas unidades do CEFET/RJ nos últimos anos que ajudam a propiciar à integração social interna e externa realizadas pela instituição como: Roda de Conversa on-line "CON-viver: Pessoas e Diversidades" - Núcleo de Apoio às Pessoas com Necessidades Específicas (NAPNE) e Mesa Redonda sobre Igualdade Racial (campus Petrópolis); 
Semana de Luta da Pessoa com Deficiência - NAPNE e Ciclo de Palestras do Programa de Pós-Graduação em Relações Étnico-Raciais: Por uma Educação Antirracista (campus Maracanã). Foram verificadas diversas ações que propiciam a integração por meio do senso comunitário como: Bazar para ajudar famílias de crianças em tratamento médico (campus Maria da Graça) e Arrecadação de água mineral para a população de Mariana (MG)-2015 (campus Nova Iguaçu).

O CEFET/RJ (campus Maracanã) oferece aulas de Jiu Jitsu para alunos, servidores, terceirizados e comunidade externa. A Divisão de Atenção à Saúde e Perícias (DASPE) realiza exames periódicos de Saúde em servidores, elabora palestras sobre prevenção de doenças e nutrição, oferece serviços de acompanhamento nutricional e na área de segurança e medicina do trabalho realiza a Semana Interna de Prevenção de Acidentes de Trabalho (SIPAT). Como ações realizadas de Promoção a saúde pela instituição, temos: Palestras sobre DST's (campus Valença), Ciclo de debates: Nutrição e Vegetarianismo (campus Itaguaí), Ações de combate ao Aedes Aegypti (campus Angra dos Reis, Maria da Graça e Nova Iguaçu), Covid-19: Conversando para se prevenir (campus Petrópolis) e Campanha para Rastreio de Diabetes e Hipertensão (campus Maracanã).

\subsubsection{ANÁLISE DO EIXO 4 - SENSIBILIZAÇÃO E CAPACITAÇÃO DE SERVIDORES}

Na Figura 7 são mostrados os resultados da pesquisa referentes às perguntas do Eixo 4 da A3P e a aderência da instituição ao eixo. 
Figura 7 - Eixo 4 da A3P - Resultados da pesquisa

\begin{tabular}{|c|c|c|c|}
\hline \multicolumn{4}{|c|}{ Eixo 4 - Sensibilização e Capacitação de servidores. } \\
\hline Perguntas & $\begin{array}{c}\text { SIM } \\
\text { (Quant. - \%) }\end{array}$ & $\begin{array}{c}\text { NÃO } \\
\text { (Quant. - \%) }\end{array}$ & $\begin{array}{c}\text { NÃO } \\
\text { RESPONDIDO }\end{array}$ \\
\hline $\begin{array}{l}\text { O CEFET/RJ elabora ações para sensibilizar } \\
\text { os servidores técnicos administrativos quanto } \\
\text { à responsabilidade socioambiental? }\end{array}$ & $7-47 \%$ & $8-53 \%$ & \\
\hline $\begin{array}{l}\text { O CEFET/RJ elabora ações para capacitar } \\
\text { os servidores técnicos administrativos quanto } \\
\text { à responsabilidade socioambiental? }\end{array}$ & $5-33 \%$ & $10-67 \%$ & \\
\hline $\begin{array}{l}\text { O CEFET/RJ elabora ações para sensibilizar } \\
\text { os servidores docentes quanto à } \\
\text { responsabilidade socioambiental? }\end{array}$ & $6-40 \%$ & $8-53 \%$ & $1-7 \%$ \\
\hline $\begin{array}{l}\text { O CEFET/RJ elabora ações para capacitar } \\
\text { os servidores docentes quanto à } \\
\text { responsabilidade socioambiental? }\end{array}$ & $5-33 \%$ & $9-60 \%$ & $1-7 \%$ \\
\hline $\begin{array}{l}\text { Há sensibilização dos gestores no CEFET/RJ } \\
\text { com relação às questões socioambientais? }\end{array}$ & $9-60 \%$ & $6-40 \%$ & \\
\hline $\begin{array}{l}\text { O CEFET/RJ fomenta a educação ambiental } \\
\text { ao corpo discente em todos os niveis de } \\
\text { ensino? }\end{array}$ & $6-40 \%$ & $7-47 \%$ & $2-13 \%$ \\
\hline $\begin{array}{l}\text { O CEFET/RJ fomenta ações de } \\
\text { sensibilização da comunidade no entorno da } \\
\text { instituição no que compreende a } \\
\text { conservação, recuperação e melhoria do } \\
\text { meio ambiente? }\end{array}$ & $2-13 \%$ & $12-80 \%$ & $1-7 \%$ \\
\hline $\begin{array}{l}\text { O CEFET/RJ realiza a produção de material } \\
\text { educativo voltado à preservação e } \\
\text { conservação do meio ambiente? }\end{array}$ & $7-46 \%$ & $7-47 \%$ & $1-7 \%$ \\
\hline $\begin{array}{l}\text { O CEFET/RJ realiza a divulgação de material } \\
\text { educativo voltado à preservação e } \\
\text { conservação do meio ambiente? }\end{array}$ & $7-46 \%$ & $7-47 \%$ & $1-7 \%$ \\
\hline Aderência ao Eixo 4 & $54-40 \%$ & $74-55 \%$ & $7-5 \%$ \\
\hline
\end{tabular}

Fonte: Adaptado de Freitas et al.,(2011), Vasconcelos (2015) e MMA (2017)

A partir da análise da Figura 7, a aderência da instituição ao Eixo 4 (Sensibilização e Capacitação de Servidores) da A3P é parcial e corresponde a $40 \%$ de todo o eixo. No que se refere à elaboração de ações para sensibilizar e capacitar os servidores técnicos administrativos e docentes quanto à responsabilidade socioambiental por parte do CEFET/RJ, a maioria dos servidores considera que a instituição não desenvolve ações para sensibilizar e capacitar. No que concerne ao fomento da sensibilização dos gestores da instituição com relação às questões ambientais e de ações de sensibilização da comunidade no entorno da instituição no que compreende

Disponível em: https://www.nucleodoconhecimento.com.br/engenharia-de-producao/logistica- 
a conservação, recuperação e melhoria do meio ambiente, a maioria dos respondentes considera que o CEFET/RJ incentiva à sensibilização dos gestores e não fomenta as ações de sensibilização da comunidade no entorno. Para $47 \%$ dos servidores a instituição não incentiva a educação ambiental do corpo discente em todos os níveis de ensino e não realiza a produção e a divulgação de material educativo voltado para a preservação e conservação do meio ambiente.

Ao analisar a aplicação da legislação ambiental nas atividades socioambientais do CEFET/RJ foi observado que a instituição seguiu as diretrizes da Lei oㅜ 9.795/1999 que instituiu a Política Nacional de Educação Ambiental, realizou projetos de ensino, pesquisa e extensão e ofertou cursos para servidores. Foi evidenciado que a DISAI realizou diversas ações e projetos voltados para as questões ambientais com o intuito de sensibilizar a comunidade interna e externa. Alguns exemplos: Projeto SERFET SUSTENTÁVEL, Encontro do Meio Ambiente no CEFET/RJ (2017), Palestras Semestrais para os Alunos dos Primeiros Períodos dos Cursos Superiores e do Integrado (Médio/Técnico) do CEFET/RJ (Possui o objetivo de conscientizar os alunos sobre a importância da sustentabilidade e a forma correta de descarte dos resíduos), Rodas de Conversa de Sustentabilidade Ambiental Institucional e o Projeto Sala Verde que tem a finalidade de evidenciar a importância da sustentabilidade nas ações e iniciativas desenvolvidas no processo educativo (ensino, pesquisa e extensão). A DISAI em parceria com a Divisão de Capacitação e Desenvolvimento (DICAP) do Departamento de Gestão de Pessoas (DGP) do CEFET/RJ e com o Projeto Sala Verde do MMA ofertou e indicou alguns cursos presenciais e à distância para a capacitação de servidores nas questões relativas à gestão socioambiental.

\subsubsection{ANÁlISE DO EIXO 5 - CONTRATAÇÕES PÚBliCAS SUSTENTÁVEIS}

Nas Figuras 8 e 9 são mostrados os resultados da pesquisa referentes às perguntas do Eixo 5 da A3P e a aderência da instituição ao eixo. 
Figura 8 - Eixo 5 da A3P - Resultados da pesquisa

Parte 2 - Eixos temáticos da A3P.

Eixo 5 - Contratações Públicas Sustentáveis.

Grupo 1 - Compras Públicas Sustentáveis.

\begin{tabular}{l|c|c|c}
\hline Perguntas & $\begin{array}{c}\text { SIM } \\
\text { (Quant. - \%) }\end{array}$ & $\begin{array}{c}\text { Ñ̃O } \\
\text { (Quant. - \%) }\end{array}$ & $\begin{array}{c}\text { NẼO } \\
\text { RESONDIDO }\end{array}$ \\
\hline $\begin{array}{l}\text { Na aquisição de bens o CEFET/RJ observa } \\
\text { se o produto foi produzido com um menor } \\
\text { consumo de matéria prima e uma maior }\end{array}$ & $3-20 \%$ & $9-60 \%$ & $3-20 \%$ \\
quantidade de recicláveis? & & &
\end{tabular}

Fonte: Adaptado de Freitas et al.,(2011), Vasconcelos (2015) e MMA (2017)

Disponível em: https://www.nucleodoconhecimento.com.br/engenharia-de-producao/logisticasustentavel 
Figura 9 - Eixo 5 da A3P - Resultados da pesquisa (conclusão)

Parte 2 - Eixos temáticos da A3P.

Eixo 5 - Contratações Públicas Sustentáveis.

Grupo 1 -Compras Públicas Sustentáveis.

Perguntas

Na aquisição de bens o CEFET/RJ dá uma maior prioridade para produtos fabricados por fontes não poluidoras e materiais que não prejudiquem o meio ambiente?

$\mathrm{Na}$ aquisição de bens o CEFET/RJ usa como critério avaliativo a existência da Certificação Ambiental por parte das empresas participantes e produtoras? O CEFET/RJ adquire produtos reciclados? $\mathrm{Na}$ aquisição de bens o CEFET/RJ leva em consideração a qualidade e a durabilidade dos produtos?

O CEFET/RJ dá preferência à aquisição de bens/produtos que possam ser reutilizados, reciclados ou reabastecidos?

O CEFET/RJ na aquisição de equipamentos eletroeletrônicos observa os critérios estabelecidos na Resolução CONAMA n ${ }^{\circ}$ 20 de 07/12/94 que estabeleceu o selo ruido?

O CEFET/RJ sempre que possivel realiza as licitações através do pregão eletrônico?

\begin{tabular}{|c|c|c|}
\hline $\begin{array}{c}\text { SIM } \\
\text { (Quant. - \%) }\end{array}$ & $\begin{array}{c}\text { NÃO } \\
\text { (Quant. - \%) }\end{array}$ & $\begin{array}{c}\text { NÃO } \\
\text { RESPONDIDO }\end{array}$ \\
\hline $4-27 \%$ & $8-53 \%$ & $3-20 \%$ \\
\hline $5-33 \%$ & $7-47 \%$ & $3-20 \%$ \\
\hline $6-40 \%$ & $6-40 \%$ & $3-20 \%$ \\
\hline $7-47 \%$ & $5-33 \%$ & $3-20 \%$ \\
\hline $6-40 \%$ & $6-40 \%$ & $3-20 \%$ \\
\hline $8-53 \%$ & $3-20 \%$ & $4-27 \%$ \\
\hline $12-80 \%$ & $3-20 \%$ & \\
\hline
\end{tabular}

Grupo 2 - Contratações Públicas Sustentáveis.

Na contratação de serviços públicos o CEFET/RJ exige em seus editais que a empresa forneça treinamento aos seus empregados?

Na contratação de serviços públicos o CEFET/RJ exige que as empresas utilizem equipamentos de limpeza que não gerem ruidos?

Na contratação de serviços públicos o CEFET/RJ exige que as empresas no cumprimento de suas atividades forneçam aos empregados os equipamentos de segurança necessários?

Na contratação de serviços públicos o CEFET/RJ exige que as empresas realizem a separação dos residuos sólidos descartados?

Na contratação de serviços públicos o CEFET/RJ exige que as empresas adotem medidas para reduzir o consumo de água e energia?

Aderência ao Eixo 5

\begin{tabular}{|l|l|l}
\hline $8-53 \%$ & $3-20 \%$ & $4-27 \%$ \\
\hline $6-40 \%$ & $5-33 \%$ & $4-27 \%$ \\
\hline $9-60 \%$ & $3-20 \%$ & $3-20 \%$ \\
\hline $4-27 \%$ & $7-46 \%$ & $4-27 \%$ \\
\hline $7-46 \%$ & $4-27 \%$ & $4-27 \%$ \\
\hline $\mathbf{8 5 - 4 4 \%}$ & $69-35 \%$ & $41-21 \%$
\end{tabular}

Fonte: Adaptado de Freitas et al.,(2011), Vasconcelos (2015) e MMA (2017)

Disponível em: https://www.nucleodoconhecimento.com.br/engenharia-de-producao/logistica- 
Considerando as informações contidas nas Figuras 8 e 9, a aderência da instituição ao Eixo 5 (Contratações Públicas Sustentáveis) da A3P é parcial e corresponde a 44\% de todo o eixo. No que se refere às Compras Públicas Sustentáveis realizadas pelo CEFET/RJ, a maioria dos servidores respondentes considera que a instituição ao adquirir bens, produtos e equipamentos sempre que possível realiza as licitações através da modalidade Pregão Eletrônico, na aquisição de equipamentos eletroeletrônicos observa os critérios da Resolução CONAMA oo 20 de 07/12/1994 (Selo Ruído), não observa se o produto foi produzido com um menor consumo de matéria prima e uma maior quantidade de recicláveis e não dá prioridade para produtos fabricados por fontes não poluidoras e materiais que não prejudiquem o meio ambiente. Para $47 \%$ dos servidores, o CEFET/RJ ao adquirir bens leva em consideração à qualidade e a durabilidade dos produtos e não usa como critério avaliativo a existência da Certificação Ambiental por parte das empresas participantes e produtoras. Com relação à preferência por parte da instituição em adquirir bens/produtos reciclados e que possam ser reutilizados, reciclados ou reabastecidos, as respostas ficaram dívidas, $40 \%$ dos servidores consideram que o CEFET/RJ dá preferência, $40 \%$ consideram que não e $20 \%$ não responderam. No que concerne as Contratações Públicas Sustentáveis realizadas pela instituição, a maioria dos respondentes considera que o CEFET/RJ exige em seus editais que a empresa forneça treinamento aos seus empregados e que no cumprimento de suas atividades forneça aos seus empregados equipamentos de segurança necessários. Para $46 \%$ dos servidores, a instituição ao contratar serviços exige que as empresas adotem medidas para reduzir o consumo de energia e água e não exige que realizem a separação dos resíduos sólidos descartados e 40\% acreditam que o CEFET/RJ exige que as empresas utilizem equipamentos de limpeza que não gerem ruídos.

Ao analisar a aplicação da legislação ambiental nas atividades socioambientais do CEFET/RJ foi observado que a instituição segue as orientações do Decreto no 7.746/2012 alterado pelo Decreto № 9.178/2017 que regulamenta o art. 3을 Lei $n^{\circ}$ 8.666/1993 e estabelece critérios e práticas sustentáveis nas contratações realizadas pela administração pública federal, segue a Instrução Normativa № 01/2010 que 
dispõe sobre os critérios de sustentabilidade ambiental na aquisição de bens, contratação de serviços ou obras pela Administração Pública Federal e segue a Lei no 12.305/2010. Foi verificado que a instituição estabelece especificações com características sustentáveis nos seus Termos de Referência dos editais para aquisição de bens e contratação de serviços. No Termo de Referência dos editais desenvolvidos e organizados pelo CEFET/RJ, foi criado um subcapítulo chamado de Critérios de Sustentabilidade Ambiental que é baseado no Capítulo III do Art. 5 da Instrução Normativa SLTI/MPOG 01/2010 e no Art. 2º e Art. 4º do Decreto 9.178/2017. Nos editais constam que a instituição prioriza a aquisição de bens reciclados ou bens que foram produzidos por fontes não poluidoras, com um menor consumo de matéria prima, uma maior quantidade de recicláveis, que não prejudiquem o meio ambiente e que tenham Certificação Ambiental. No ano de 2017, o percentual de licitações que possuíam critérios e declarações de sustentabilidade correspondia a $25 \%$ do total, em 2020 este percentual passou para $95 \%$ do total.

\subsubsection{ANÁLISE DO EIXO 6 - CONSTRUÇÕES SUSTENTÁVEIS}

Na Figura 10 são mostrados os resultados da pesquisa referentes às perguntas do Eixo 6 da A3P e a aderência da instituição ao eixo. 
Figura 10 - Eixo 6 da A3P - Resultados da pesquisa

\begin{tabular}{|c|c|c|c|}
\hline \multicolumn{4}{|l|}{ Eixo 6 - Construções Sustentáveis. } \\
\hline Perguntas & $\begin{array}{c}\text { SIM } \\
\text { (Quant. - \%) } \\
\end{array}$ & $\begin{array}{c}\text { NÃO } \\
\text { (Quant. - \%) }\end{array}$ & $\begin{array}{c}\text { NÃO } \\
\text { RESPONDIDO }\end{array}$ \\
\hline $\begin{array}{l}\text { No CEFET/RJ as edificações possuem } \\
\text { automação da iluminação (Sensores de } \\
\text { Presença, iluminação tarefa,...)? }\end{array}$ & $1-6 \%$ & $13-87 \%$ & $1-7 \%$ \\
\hline $\begin{array}{l}\text { O CEFET/RJ faz o aproveitamento da água } \\
\text { da chuva através de estruturas de captação, } \\
\text { transporte e armazenamento? }\end{array}$ & $2-13 \%$ & $12-80 \%$ & $1-7 \%$ \\
\hline $\begin{array}{l}\text { O CEFET/RJ exige a comprovação da } \\
\text { origem da madeira utilizada na execução de } \\
\text { obras ou serviços? }\end{array}$ & $2-13 \%$ & $9-60 \%$ & $4-27 \%$ \\
\hline $\begin{array}{l}\text { O CEFET/RJ utiliza alguma fonte de energia } \\
\text { renovável (energia solar, energia eólica,...)? }\end{array}$ & $1-7 \%$ & $12-80 \%$ & $2-13 \%$ \\
\hline $\begin{array}{l}\text { O CEFET/RJ possui salas de trabalho e de } \\
\text { aula com algum tipo de parede de proteção } \\
\text { contra ruidos externos? }\end{array}$ & $3-20 \%$ & $10-67 \%$ & $2-13 \%$ \\
\hline $\begin{array}{l}\text { O CEFET/RJ faz uso de material ou } \\
\text { equipamento reciclado ou reutilizado? }\end{array}$ & $5-34 \%$ & $8-53 \%$ & $2-13 \%$ \\
\hline Aderência ao Eixo 6 & $14-16 \%$ & $64-71 \%$ & $12-13 \%$ \\
\hline
\end{tabular}

Fonte: Adaptado de Freitas et al.,(2011), Vasconcelos (2015) e MMA (2017)

Considerando as informações contidas na Figura 10, a aderência do CEFET/RJ ao Eixo 6 (Construções Sustentáveis) da A3P é parcial e corresponde a 16\% de todo o eixo. Para a maioria dos servidores participantes da pesquisa as edificações da instituição não possuem automação da iluminação (Sensores de Presença, lluminação Tarefa...) que resultam em economia de energia elétrica, o CEFET/RJ não realiza o aproveitamento da água da chuva através de estruturas de captação, transporte e armazenamento e não utiliza nenhuma fonte de energia renovável (Energia Solar, Energia Eólica,...). A respeito da exigência por parte da instituição da comprovação da origem da madeira utilizada na execução de obras ou serviços, a maioria dos respondentes considera que o CEFET/RJ não exige a comprovação. Para $67 \%$ dos servidores a instituição não possui salas de trabalho e de aula com algum tipo de parede de proteção contra ruídos externos e para a maioria dos servidores a instituição não faz uso de material ou equipamento reciclado ou reutilizado.

Disponível em: https://www.nucleodoconhecimento.com.br/engenharia-de-producao/logistica- 
Ao analisar a aplicação da legislação ambiental nas atividades socioambientais do CEFET/RJ foi observado que a instituição tem seguido a IN № 01/2010 em seus Projetos Básicos e Executivos de Reformas e a IN no 02/2014 que trata de regras para compra ou aluguel de máquinas e aparelhos consumidores de energia pela Administração Pública Federal e uso da Etiqueta Nacional de Conservação de Energia (ENCE) nos projetos de novas edificações ou que recebam retrofit. Foi evidenciado que no início de fevereiro de 2019 foi instalado no CEFET/RJ (campus Maracanã) um Coletor de Águas Pluviais. Segundo a chefe da DISAI, no futuro novos coletores serão viabilizados em outras unidades da instituição. Foi constatado que a instituição na contratação de serviços, obras e em seus projetos básicos e executivos de reformas utiliza diversos critérios na execução dos serviços como: Tipos de materiais utilizados, origem das madeiras utilizadas, o uso de equipamentos de proteção coletiva e individual, tipos de torneiras e vasos sanitários e tipo de tinta para pintura.

\subsubsection{INCENTIVOS E OBSTÁCULOS À IMPLANTAÇÃO DAS AÇÕES DE RESPONSABILIDADE SOCIOAMBIENTAL NA INSTITUIÇÃO.}

Para análise das duas perguntas voltadas para a instituição referente à Parte 3 do questionário foi elaborada uma tabela mostrada na Figura 11 que visa verificar a percepção dos servidores com relação aos três maiores incentivos e obstáculos à implantação das ações de Responsabilidade Socioambiental no CEFET/RJ. 
Figura 11 - Maiores Incentivos e Obstáculos à implementação das ações na instituição

- Resultados da pesquisa

Parte 3 - Incentivos e Obstáculos à implantação das ações de responsabilidade socioambiental na instituição.

Identifique os três maiores INCENTIVOS à implantação das ações de Responsabilidade Socioambiental no CEFET/RJ.

\begin{tabular}{|c|c|c|}
\hline Opções de Resposta & $\begin{array}{c}\text { Total de } \\
\text { Questionários }\end{array}$ & $\begin{array}{l}\text { Percentual } \\
(\%)\end{array}$ \\
\hline $\begin{array}{l}\text { Adaptação às exigências da legislação } \\
\text { ambiental. }\end{array}$ & 12 & $\mathbf{8 0} \%$ \\
\hline Senso de responsabilidade socioambiental. & 10 & $67 \%$ \\
\hline Redução de custos. & 11 & $73 \%$ \\
\hline Monitoramento da performance ambiental. & 2 & $13 \%$ \\
\hline $\begin{array}{l}\text { Vantagens regulatórias ao reduzir a ocorrência de } \\
\text { acidentes ambientais. }\end{array}$ & 1 & $7 \%$ \\
\hline $\begin{array}{l}\text { Proteção dos interesses da instituição (Finalidade } \\
\text { de melhorar a imagem da instituição). }\end{array}$ & 4 & $27 \%$ \\
\hline $\begin{array}{l}\text { Pressão da opinião pública e/ou alta } \\
\text { administração. }\end{array}$ & 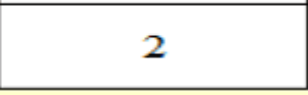 & $13 \%$ \\
\hline \multicolumn{3}{|c|}{$\begin{array}{l}\text { Identifique os três maiores OBSTÁCULOS na elaboração e na } \\
\text { implantação das ações de sustentabilidade no CEFET/RJ. }\end{array}$} \\
\hline Carência de recursos financeiros. & \begin{tabular}{|l|}
9 \\
\end{tabular} & $60 \%$ \\
\hline Descentralização/fragmentação institucional. & 6 & $40 \%$ \\
\hline $\begin{array}{l}\text { Conflito de interesses entre grupos (docentes, } \\
\text { técnicos administrativos e discentes). }\end{array}$ & 3 & $20 \%$ \\
\hline Burocracia excessiva. & 6 & $40 \%$ \\
\hline $\begin{array}{l}\text { Dificuldades de persuasão à participação de } \\
\text { todos. }\end{array}$ & 9 & $60 \%$ \\
\hline Resultados em longo prazo. & 4 & $27 \%$ \\
\hline Falta de suporte da Alta Administração. & 4 & $27 \%$ \\
\hline Outros especificar: falta de infraestrutura. & 1 & $7 \%$ \\
\hline
\end{tabular}

Fonte: Adaptado de Vasconcelos (2015)

Considerando as informações contidas na Tabela 8, foi evidenciado que os servidores respondentes da pesquisa consideram como os três maiores incentivos à implantação das ações de Responsabilidade Socioambiental no CEFET/RJ: Adaptação às exigências da legislação ambiental (80\%), a redução de custos (73\%) e o senso de responsabilidade socioambiental (67\%). Com relação aos três maiores obstáculos na elaboração e na implantação das ações de sustentabilidade na instituição, os respondentes consideraram: A carência de recursos financeiros (60\%), as dificuldades de persuasão à participação de todos (60\%), a descentralização/fragmentação

Disponível em: https://www.nucleodoconhecimento.com.br/engenharia-de-producao/logistica- 
institucional (40\%) e a burocracia excessiva (40\%). Foi considerada também a burocracia excessiva como um dos maiores obstáculos, pois teve a mesma quantidade de respostas que o terceiro maior respondido.

\subsubsection{ANÁLISE DA ADERÊNCIA DO PLS DO CEFET/RJ E AS AÇÕES PROPOSTAS DA A3P}

Para análise das práticas sustentáveis do PLS que foram adotadas na instituição foi necessário verificar primeiramente se o PLS do CEFET/RJ seguiu os temas mínimos a serem abrangidos conforme o Art. 8ㅇ da IN № 10 de 12 de novembro de 2012. Podemos afirmar que o PLS da instituição seguiu os temas mínimos exigidos pelo Art. 8 da IN no 10 de 12 de novembro de 2012. Com relação ao conteúdo mínimo que deve compor um PLS segundo o Art. 5ํ da IN no 10/2012, o PLS da instituição possui: Práticas de sustentabilidade e de racionalização no uso de materiais e serviços; Responsabilidades, metodologia de implementação e avaliação do plano; Atualização do inventário de bens e materiais e identificação de similares de menor impacto ambiental para substituição. As ações de divulgação, conscientização e capacitação não se encontram especificadas ao longo do PLS, mas a realização de ações por parte da instituição é mencionada como um dos objetivos específicos do PLS do CEFET/RJ. A IN no 10/2012, em seu Art. 9ㅇ, descreve que para cada tema mencionado do Art. 8ㅜ, que for adicionado ao PLS deverão ser criados Planos de ações contendo tópicos. No PLS da instituição foram criados para cada Eixo Temático Projeto, um grupo ou diversos grupos. Para cada grupo foram criados planos de ação com os tópicos sugeridos pelo Art. 9ํ da IN no 10/2012. Com relação ao tópico VI do referido artigo, o PLS da instituição não especifica a previsão de recursos financeiros, humanos, instrumentais, entre outros, necessários para a implementação das ações. No que concerne $\circ \S^{2^{\circ}}$ do Art. 9 , caso o órgão ou entidade inclua outros temas em seu PLS, deverão incluir indicadores com especificações. No PLS do CEFET/RJ, para cada grupo foram criados planos de ação. Para cada plano de ação foram definidos diversos indicadores de monitoramento contendo todos os elementos especificados

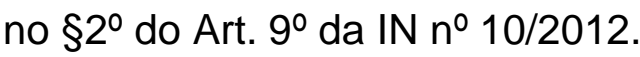


Os indicadores de desempenho foram definidos para cada eixo temático, tendo como referência a sua correlação com os Objetivos de Desenvolvimento Sustentável (ODS) da Agenda 2030 e suas metas, visando monitorar a eficiência das iniciativas e ações descritas. Foi observado que dos 53 índices de monitoramento definidos para o cumprimento dos objetivos e metas do PLS do CEFET/RJ, 17 índices foram utilizados e 36 não. Com relação aos índices de monitoramento pertencentes aos Eixos Temáticos Projeto do PLS foi evidenciado que a instituição somente utiliza alguns índices de monitoramento pertencentes a cada Eixo. Os dois índices de monitoramento pertencentes ao Eixo Temático Projeto de Obras e Construções Sustentáveis, os cinco índices do grupo Impressão de Documentos, os 10 índices do grupo Serviços Administrativos e os quatro índices do grupo Consumo de Copos Descartáveis pertencentes ao Eixo Temático Projeto Compras e Contratações Sustentáveis não são utilizados. No que concerne aos índices pertencentes ao grupo Consumo de papel do Eixo Temático Projeto Compras e Contratações Sustentáveis são todos utilizados. Segundo informações obtidas da DISAI, primeiramente foram utilizados alguns índices para o monitoramento das ações do PLS exigidos pelo Sistema de Monitoramento do MMA (RESSOA A3P) e que futuramente serão introduzidos os demais índices propostos no PLS para o monitoramento das ações, mas para isso se faz necessária à obtenção de informações periódicas enviadas por outras diretorias da instituição. Após a análise fica evidenciado que a maioria dos indicadores de desempenho das ações descritas para cada eixo temático, ainda não são utilizados para a realização de um monitoramento eficaz do PLS, sugerindo uma possível dificuldade na implementação desse monitoramento nas unidades do CEFET/RJ.

\section{CONCLUSÃO}

$\mathrm{Na}$ realização desta pesquisa ficou evidente que as IFEs possuem um papel fundamental na disseminação do conhecimento e no desenvolvimento de uma sociedade mais sustentável. Em busca de incorporar princípios, práticas de sustentabilidade, sensibilizar docentes, funcionários e alunos e atender ao art. 16으 do decreto 7.746/2012 alterado pelo decreto $9.178 / 2017$ e ao art. $12^{\circ}$ da Instrução 
Normativa no 10/2012, o CEFET/RJ aderiu a Agenda A3P e aprovou e publicou o PLS que permite a instituição estabelecer práticas de sustentabilidade e racionalização de gastos e processos na Administração Pública estabelecendo objetivos, responsabilidades, ações, metas, prazos de execução e mecanismos de monitoramento e avaliação.

Considerando a problemática da pesquisa que tem relação com a melhoria no processo de implementação do PLS em uma instituição de ensino, de acordo com as legislações ambientais vigentes e seguindo as ações propostas na Agenda A3P e no que concerne os resultados apresentados na seção 4 foi possível sugerir diversas melhorias que são descritas ao longo desta seção.

A respeito da aplicação da legislação ambiental nas atividades socioambientais do CEFET/RJ foi constatado que o CEFET/RJ seguiu as principais diretrizes das legislações recomendadas pela A3P. Entre as leis, decretos e instruções normativas, temos: A Lei 12.305/2010 (Política Nacional dos Resíduos Sólidos), o Decreto no 5.940/2006 (Separação dos Resíduos Recicláveis e a sua destinação para associações e cooperativas de catadores de materiais recicláveis), o Decreto $\mathrm{n}^{0}$ 7.746/2012 alterado pelo Decreto ํㅜ 9.178/2017 que regulamenta o art. 3o da Lei $n^{\circ}$ 8.666/1993 e estabelece critérios e práticas sustentáveis nas contratações realizadas pela administração pública federal e a IN no 01/2010 que dispõe sobre os critérios de sustentabilidade ambiental na aquisição de bens, contratação de serviços ou obras pela Administração Pública Federal.

No que concerne à mensuração das ações propostas na agenda A3P por parte da instituição, foi verificado primeiramente a aderência do CEFET/RJ aos objetivos principais da A3P. Foi possível inferir que a maioria dos servidores respondentes da pesquisa concorda totalmente e parcialmente que a Gestão ambiental da instituição fomenta a sensibilização dos gestores, proporciona o uso adequado dos recursos naturais e dos bens públicos e colabora com a adoção de novos referenciais de sustentabilidade. Em se tratando da adesão do CEFET/RJ aos eixos temáticos da A3P, mediante a percepção dos servidores, foi verificado que apesar da baixa taxa de 
aderência ao Eixo 1 (Uso Racional dos Recursos Naturais e Bens Públicos), a instituição realiza campanhas para o uso racional de água e energia, realiza o monitoramento e a redução do consumo de papel e que há preferência no uso de documentos digitalizados e de mensagens eletrônicas (e-mail) na comunicação e nos atos de expediente. Diante da análise da aplicação da legislação ambiental nas atividades do CEFET/RJ e as informações contidas no Relatório de Sustentabilidade do CEFET/RJ 2020 podemos constatar que o CEFET/RJ (campus Maracanã) realiza o monitoramento e a redução do consumo de água e energia. Dessa forma, podemos concluir que se faz necessário uma melhor implementação do monitoramento nas demais unidades da instituição e que a programação de todas as impressoras para imprimir frente e verso é imprescindível para a redução dos gastos com papel na impressão de documentos.

Com relação à percepção dos servidores ao Eixo 2 (Gestão adequada dos Resíduos Gerados), a instituição não pratica a Política dos 5R's e não realiza o levantamento do volume de resíduos gerados. No entanto, foi possível verificar que a instituição realiza diversas ações incentivando a política dos 5R's como: Coleta Seletiva Solidária e mutirões sustentáveis. Em relação ao levantamento do volume dos resíduos gerados foi verificado que somente é realizado pelo CEFET/RJ (campus Maracanã). Já nas demais unidades se faz necessário uma melhor implementação deste levantamento. Foi evidenciando a importância e a necessidade de uma melhor divulgação das ações por parte da instituição resultando em uma melhor percepção por parte dos servidores. A respeito da aderência da instituição ao Eixo 3 (Qualidade de Vida no Ambiente de Trabalho) foi verificado após a análise dos resultados que a maioria dos servidores considera que a instituição usa e estimula a capacitação aproveitando as habilidades individuais e coletivas dos servidores e incentiva a capacitação através da autonomia nas atividades a serem desempenhadas. A respeito da integração social interna e externa, a maioria dos respondentes considera que o CEFET/RJ fomenta e propicia uma integração social interna e externa sem preconceitos e promove e incentiva uma integração social interna favorecendo os relacionamentos interpessoais. No que concerne o Respeito à legislação, os 
servidores respondentes da pesquisa consideram que a instituição respeita e estimula a liberdade de expressão, a privacidade pessoal e o tratamento imparcial. Em relação às Condições de Segurança e Saúde no Trabalho, a maioria dos servidores considera que o CEFET/RJ não se preocupa com a ergonomia dos equipamentos e mobiliários usados pelos servidores e estagiários, que as instalações da instituição não atendem a todas as exigências de acesso para os portadores de deficiência física e que a instituição não oferece aos servidores e estagiários atividades de ginástica laboral e outras atividades semelhantes. Entretanto, foram verificadas diversas ações que buscam a melhoria na qualidade de vida no ambiente de trabalho podemos constatar que o CEFET/RJ (campus Maracanã) oferece aulas de Jiu Jitsu para alunos, servidores, terceirizados e comunidade externa e a DASPE realiza exames periódicos de Saúde em servidores, elabora palestras sobre prevenção de doenças e nutrição e oferece serviços de acompanhamento nutricional. Visando atender as necessidades dos servidores identificadas na análise dos resultados de Eixo 3, podemos sugerir algumas ações de melhoria a serem implementadas, como: a substituição dos equipamentos e mobiliários da instituição por outros mais ergonômicos, uma melhoria nas instalações das unidades do CEFET/RJ com relação à acessibilidade por parte dos portadores de deficiência física (construção de rampas, corrimãos,...) e o oferecimento de atividades de ginástica laboral e outras atividades semelhantes para os servidores e estagiários de todas as unidades da instituição.

$\mathrm{Na}$ análise da aderência do CEFET/RJ ao Eixo 4 (Sensibilização e Capacitação de Servidores) a maioria dos servidores considera que a instituição promove à sensibilização dos seus gestores com relação às questões socioambientais, mas não elabora ações para capacitar servidores técnicos administrativos e não fomenta ações de sensibilização da comunidade no entorno da instituição. No entanto foi verificado que a DISAI realizou ações e projetos voltados para as questões ambientais com o intuito de sensibilizar a comunidade interna e externa. Para melhorar a percepção dos servidores em relação ao Eixo 4, podemos sugerir algumas ações de melhoria a serem implementadas, como: uma oferta maior por parte da instituição de cursos, palestras e eventos com o intuito de sensibilizar e capacitar o público interno (servidores, 
docentes e alunos) e o público externo e a ampliação por parte da instituição da produção e divulgação de material educativo voltado à preservação e conservação do meio ambiente. No que concerne à aderência da instituição ao Eixo 5 (Contratações Públicas Sustentáveis) foi verificado pela percepção dos servidores que o CEFET/RJ ao adquirir bens, não verifica se os mesmos foram fabricados com menor consumo de matéria prima e uma maior quantidade de recicláveis, não prioriza produtos fabricados por fontes não poluidoras e com materiais que não prejudiquem o meio ambiente, ao adquirir equipamentos eletroeletrônicos observa os critérios estabelecidos pela Resolução CONAMA oㅡ 20 de 07/12/94 (selo ruído) e sempre que possível realiza suas licitações através do Pregão Eletrônico. A respeito das Contratações Públicas Sustentáveis, a maioria dos respondentes da pesquisa considera que a instituição ao contratar serviços públicos exige em seus editais que as empresas forneçam treinamento aos seus empregados e exige das empresas contratadas que no cumprimento de suas atividades forneçam aos seus empregados os equipamentos de segurança necessários. Com a análise das informações coletadas na instituição, foi possível verificar o cumprimento da legislação vigente e o estabelecimento de especificações com características sustentáveis nos seus Termos de Referência dos editais para aquisição de bens e contratação de serviços. Os servidores respondentes da pesquisa parecem não ter conhecimento sobre algumas ações que foram implantadas no CEFET/RJ pela Gestão ambiental, evidenciando a necessidade de uma melhor divulgação da realização dessas ações.

A respeito da aderência da instituição ao Eixo 6 (Construções Sustentáveis) foi verificado pela percepção da maioria dos servidores que as edificações da instituição não possuem automação da iluminação (Sensores de Presença, Iluminação Tarefa...) que resultam em economia de energia elétrica e que o CEFET/RJ não realiza o aproveitamento da água da chuva através de estruturas de captação, transporte e armazenamento. Entretanto foi verificado que no início do ano de 2019 foi instalado no CEFET/RJ (campus Maracanã) um Coletor de Águas Pluviais. Para melhorar a percepção dos servidores em relação ao Eixo 6, podemos sugerir algumas ações de melhoria a serem implementadas, como: a instalação de um sistema de automação 
da iluminação em todas as edificações das unidades do CEFET/RJ, a instalação de paredes de proteção contra ruídos externos nas salas de trabalho e de aula e a instalação de painéis fotovoltaicos nas edificações da instituição, resultando em um melhor aproveitamento da energia solar (energia renovável) e na redução nos gastos com energia elétrica. Foram verificadas também, através da percepção dos servidores, quais seriam os três maiores incentivos à implantação das ações de Responsabilidade Socioambiental no CEFET/RJ e os três maiores obstáculos na elaboração e na implantação das ações de sustentabilidade no CEFET/RJ. Para a maioria dos servidores os três maiores incentivos foram: a adaptação às exigências da legislação ambiental, a redução de custos e o senso de responsabilidade socioambiental. Como maiores obstáculos foram considerados: a carência de recursos financeiros, as dificuldades de persuasão à participação de todos, a descentralização/fragmentação institucional e a burocracia excessiva.

Com base nesses resultados fica evidente que não só a obrigatoriedade ao cumprimento das legislações ambientais e a necessidade de redução de custos por parte das IFEs, o senso de responsabilidade socioambiental também aparece como um incentivo, reafirmando a importância que esse tema apresenta para os servidores do CEFET/RJ, e para a sociedade em que vivemos. Em relação aos obstáculos ficou constatada a dificuldade para a implantação de algumas ações do PLS diante da carência de recursos financeiros recebidos pelo governo que as IFEs vêm enfrentando nos últimos anos. Com relação às dificuldades de persuasão à participação dos servidores na elaboração e no engajamento das ações do PLS fica evidente ainda a necessidade de uma participação mais efetiva dos gestores e dos servidores no processo de mudança dessa cultura organizacional, que se estabelece a longo prazo, por meio de campanhas de divulgação, oferta de cursos de capacitação, worshops e reuniões que fomentem discussões sobre o tema da sustentabilidade. A descentralização/fragmentação das unidades do CEFET/RJ e a burocracia excessiva, dificultam o processo de implementação das ações do PLS e um monitoramento eficaz, importante para identificar ajustes e melhorias a serem realizadas. Essa barreira encontrada pela descentralização das unidades evidencia a necessidade de 
que existam servidores com atribuições específicas em cada unidade do CEFET/RJ para auxiliar na implantação das ações e no monitoramento das mesmas, contribuindo assim com a unificação e a disseminação das informações.

Diante de toda a análise realizada nesse trabalho fica evidente a importância das Instituições Federais de Ensino, na implantação do PLS e da Agenda A3P de forma eficiente, visando reduzir desperdícios e conscientizando a maioria dos envolvidos no processo, contribuindo com a mudança de uma cultura organizacional necessária diante da responsabilidade que temos como cidadãos nos dias de hoje com a preservação do meio ambiente que em longo prazo resultará em um futuro melhor para as próximas gerações.

Como recomendação para pesquisas futuras, pode-se ampliar o foco da pesquisa investigando uma metodologia de monitoramento das ações do PLS que permita identificar ajustes e melhorias das ações de uma maneira mais eficaz no CEFET/RJ ou em outras instituições de ensino.

\section{REFERÊNCIAS}

BRASIL. Constituição da República Federativa do Brasil de 1988. (1988). Disponível em: <www.planalto.gov.br/ccivil_03/Constituicao/Constituicao.htm>. Acessado em: 15 de abril de 2019.

BRASIL. Decreto no 4.131, de 14 de fevereiro de 2002 (2002). Dispõe sobre medidas emergenciais de redução do consumo de energia elétrica no âmbito da Administração Pública $\quad$ Federal. Disponível em: < http://www.planalto.gov.br/ccivil_03/decreto/2002/D4131.htm>. Acessado em: 24 de abril de 2019.

BRASIL. Decreto n 5.940, de 25 de outubro de 2006 (2006). Institui a separação dos resíduos recicláveis descartados pelos órgãos e entidades da administração pública federal direta e indireta, na fonte geradora, e a sua destinação às associações e cooperativas dos catadores de materiais recicláveis, e dá outras providências. 
Disponível

em: <www.planalto.gov.br/ccivil_03/_Ato20042006/2006/Decreto/D5940.htm>. Acessado em: 16 de abril de 2019.

BRASIL. Decreto n 7.746, de 05 de junho de 2012 (2012). Regulamenta o art. 3ํ da Lei oㅜ 8.666, de 21 de junho de 1993, para estabelecer critérios, práticas e diretrizes para a promoção do desenvolvimento nacional sustentável nas contratações realizadas pela administração pública federal, e institui a Comissão Interministerial de Sustentabilidade na Administração Pública - CISAP. Casa Civil, Brasília: 2012. Disponível em: < http://www.planalto.gov.br/ccivil_03/_Ato20112014/2012/Decreto/D7746.htm>. Acessado em: 25 de abril de 2019.

BRASIL. Decreto no 9.178, de 23 de outubro de 2017 (2017). Altera o Decreto ํㅜ 7.746, de 05 de junho de 2012, que regulamenta 0 art. $3^{\circ}$ da Lei no 8.666 , de 21 de junho de 1993, para estabelecer critérios, práticas e diretrizes para a promoção do desenvolvimento nacional sustentável nas contratações realizadas pela administração pública federal direta, autárquica e fundacional e pelas empresas estatais dependentes, e institui a Comissão Interministerial de Sustentabilidade na Administração Pública - CISAP. Secretaria Geral - Subchefia para Assuntos Jurídicos, Brasília: 2017. Disponível em: < http://www.planalto.gov.br/ccivil_03/_Ato20152018/2017/Decreto/D9178.htm\#art2>. Acessado em: 25 de abril de 2019.

BRASIL. Instrução Normativa no 01, de 19 de janeiro de 2010 (2010). Dispõe sobre os critérios de sustentabilidade ambiental na aquisição de bens, contratação de serviços ou obras pela Administração Pública Federal direta, autárquica e fundacional e dá outras providências.

Disponível em: <https://www.comprasnet.gov.br/legislacao/legislacaoDetalhe.asp?ctdCod=295>. Acessado em: 16 de abril de 2019.

BRASIL. Instrução Normativa ํo 10, de 12 de novembro de 2012 (2012). Estabelece regras para elaboração dos Planos de Gestão de Logística Sustentável de que trata o art. 16, do Decreto № 7.746, de 5 de junho de 2012, e dá outras providências. Disponível 
$<$ https://www.comprasgovernamentais.gov.br/index.php/legislacao/instrucoesnormativas/394-instrucao-normativa-n-10-de-12-de-novembro-de-2012>. Acessado em: 15 de abril de 2019.

BRASIL. Instrução Normativa SLTI/MPOG nº 02, de 04 de junho de 2014 (2014). Dispõe sobre regras para a aquisição ou locação de máquinas e aparelhos consumidores de energia pela Administração Pública Federal. Disponível em: $<$ https://www.comprasgovernamentais.gov.br/index.php/pes\#repositorio-dedocumentos $>$. Acessado em: 26 de fevereiro de 2020.

BRASIL. Lei 6545, de 30 de junho de 1978 (1978). Dispõe sobre a transformação das Escolas Técnicas Federais de Minas Gerais, do Paraná e Celso Suckow da Fonseca em Centros Federais de Educação Tecnológica e dá outras providências. Disponível em: <https://www2.camara.leg.br/legin/fed/lei/1970-1979/lei-6545-30-junho-1978366492-normaatualizada-pl.html>. Acessado em: 17 de janeiro de 2020.

BRASIL. Lei 6.938, de 31 de agosto de 1981 (1981). Dispõe sobre a política nacional do meio ambiente, seus fins e mecanismos de formulação e aplicação, e dá outras providências. Disponível em: <www.planalto.gov.br/Ccivil_03/Leis/L6938.htm>. Acessado em: 17 de abril de 2019.

BRASIL. Lei no 8.666, de 21 de junho de 1993 (1993). Regulamenta o art. 37, inciso XXI, da Constituição Federal, institui normas para licitações e contratos da Administração Pública e dá outras providências. Disponível em: http://www.planalto.gov.br/ccivil_03/LEIS/L8666cons.htm>. Acessado em: 25 de abril de 2019.

BRASIL. Lei 9.433, de 08 de janeiro de 1997 (1997). Institui a Política Nacional de Recursos Hídricos, cria o Sistema Nacional de Gerenciamento de Recursos Hídricos, regulamenta o inciso XIX do art. 21 da Constituição Federal, e altera o art. $1^{\circ}$ da Lei № 8.001, de 13 de março de 1990, que modificou a Lei oㅜ 7.990, de 28 de dezembro de 1989.

Disponível

em: 
http://www.planalto.gov.br/ccivil_03/leis/19433.htm>. Acessado em: 17 de abril de 2019.

BRASIL. Lei 9.795, de 27 de abril de 1999 (1999). Dispõe sobre a educação ambiental, institui a Política Nacional de Educação Ambiental e dá outras providências. Disponível em: <www.planalto.gov.br/ccivil_03/Leis/L9795.htm >. Acessado em: 15 de abril de 2019.

BRASIL. Lei 12.305, de 02 de agosto de 2010 (2010). Institui a política nacional de resíduos sólidos; altera a lei no 9.605, de 12 de fevereiro de 1998; e dá outras providências. Disponível em:< www.planalto.gov.br/ccivil_03/_Ato20072010/2010/Lei/L12305.htm>. Acessado em: 16 de abril de 2019.

BRASIL. Ministério do Meio Ambiente (2009). A3P - Agenda Ambiental na Administração Pública. A3P. Brasília, DF, 2009. 5a Edição. Revisada e $\begin{array}{llll}\text { atualizada. } & 95 & \text { p. } & \text { Disponível em:< }\end{array}$ https://www.cuiaba.mt.gov.br/upload/arquivo/cartilha_a3p_36.pdf>. Acessado em: 15 de abril de 2019.

BRASIL. Ministério do Meio Ambiente (2020). A3P em números. 2020c. Disponível em: < http://a3p.mma.gov.br/a3p-em-numeros/>. Acessado em: 25 de fevereiro de 2020.

BRASIL. Ministério do Meio Ambiente (2017). Curso de capacitação sustentabilidade na administração pública. A3P. Brasília, DF, 2017a. 100 p. Disponível em: $\quad$ ehttp://a3p.mma.gov.br/wpcontent/uploads/Biblioteca/Documentos/Cartilha-formato-Web.pdf>. Acessado em: 28 de fevereiro de 2020.

BRASIL. Ministério do Meio Ambiente (2020). Gestão Adequada dos Resíduos Gerados. 2020a Disponível em: < http://a3p.mma.gov.br/gestao-adequada-dosresiduos-gerados/>. Acessado em: 25 de fevereiro de 2020. 
BRASIL. Ministério do Meio Ambiente (2017). Gestão socioambiental nas escolas públicas. A3P. Brasília, DF, 2017b. $34 \mathrm{p}$.

BRASIL. Ministério do Meio Ambiente (2020). História da A3P. 2020b. Disponível em: $<$ http://a3p.mma.gov.br/historia/>. Acessado em: 25 de fevereiro de 2020.

BRASIL. Ministério do Meio Ambiente (2020). Plano de Logística Sustentável (PLS). 2020d. Disponível em: < https://antigo.mma.gov.br/responsabilidadesocioambiental/a3p/item/10998-plano-de-logistica-sustentavel-pls.html/>. Acessado em: 25 de fevereiro de 2020.

BRASIL. Portaria ํㅡ 28, de 19 de fevereiro de 2018 (2018). Institui o Programa da Agenda Ambiental na Administração Pública - Programa A3P. Ministério do Meio Ambiente. Brasília: 2018. Disponível em: < http://a3p.mma.gov.br/historia/>. Acessado em: 24 de fevereiro de 2020.

BRASIL. Portaria ํo 03, de 27 de fevereiro de 2018 (2018). Institui as diretrizes do Programa da Agenda Ambiental na Administração Pública - Programa A3P. Secretaria de Articulação Institucional e Cidadania Ambiental - Ministério do Meio Ambiente. Brasília: 2018. Disponível em: < http://a3p.mma.gov.br/historia/>. Acessado em: 24 de fevereiro de 2020.

BRASIL. Resolução CONAMA o 20, de 07 de dezembro de 1994 (1994). Institui o Selo Ruído. Disponível em: < http://www.ibama.gov.br/legislacao/legislacao-seloruido?view=default $>$. Acessado em: 06 de julho de 2021.

CEFET/RJ. Campus Maracanã - Histórico. Centro Federal de Educação Tecnológica Celso Suckow da Fonseca - CEFET/RJ. 2020a. Disponível em: < http://www.cefetrj.br/index.php/campus-maracana-historico>. Acessado em 05 de março de 2020.

CEFET/RJ. Divisão de Estratégia para Sustentabilidade Ambiental Institucional (DISAI). Centro Federal de Educação Tecnológica Celso Suckow da Fonseca - 
CEFET/RJ. 2019a. Disponível em: < http://www.cefetrj.br/index.php/diges/disai>. Acessado em 04 de dezembro de 2019.

CEFET/RJ. Plano de Gestão de Logística Sustentável (PLS). Rio de Janeiro, 2018a. 55 p. Disponível em: < http://www.cefet-rj.br/index.php/plano-de-gestao-delogistica-sustentavel-pls>. Acessado em 04 de dezembro de 2019.

CEFET/RJ. Relatório de Sustentabilidade do CEFET/RJ 2020. Rio de Janeiro, 2020q. 26p.

CEFET SUSTENTÁVEL. Painel de Sustentabilidade Ambiental Institucional. Nossa História. 2020a. Disponível em: < http://sustentabilidade.sites.cefet-rj.br/historico/>. Acessado em 12 de setembro de 2020.

BRITO, Karine Soares.. A percepção da sustentabilidade pelos docentes do curso de graduação em ciência ambiental: Estudo de caso em uma instituição de ensino superior do estado do Rio de Janeiro. Dissertação (Mestrado em Sistemas de Gestão) - LATEC, Universidade Federal Fluminense, Niterói, 2017. Disponível em: < https://app.uff.br/riuff/handle/1/5437>. Acessado em: 23 de janeiro de 2020.

FREITAS, Claudio Luiz de; BORGERT, Altair; PFITSCHER, Elisete Dahmer. Agenda Ambiental da Administração Pública: uma análise da aderência de uma IFES às diretrizes propostas pela A3P. In: XI Colóquio Internacional sobre Gestão Universitária na América do Sul e II Congresso Internacional IGLU, 2011, Florianópolis. Anais do XI Colóquio Internacional sobre Gestão Universitária na América do Sul e II Congresso Internacional IGLU, p. 1-16, 2011. Disponível em: < https://repositorio.ufsc.br/xmlui/bitstream/handle/123456789/30051/7.7.pdf;sequence $=1>$. Acessado em: 06 de abril de 2020 .

HELBERT, G. L. A. Plano de Gestão de Logística Sustentável (PLS): Proposta de um Modelo para a Prefeitura Municipal de Cachoeira do Sul/RS. Dissertação do Curso de pós-graduação em Gestão de Organizações Públicas._Universidade Federal de Santa Maria (UFSM), Santa Maria - RS, 2019. Disponível em: < 
https://repositorio.ufsm.br/handle/1/19409?locale-attribute=es $>$. Acessado em: 01 de setembro de 2020.

LEVENTIS, Priscylla Abreu de Mello Demetri. Competências em gestão da sustentabilidade: Estudo de caso em uma indústria brasileira. Dissertação (Mestrado em Sistemas de Gestão) -LATEC, Universidade Federal Fluminense, Niterói, 2017. Disponível em: < https://app.uff.br/riuff/handle/1/4324>. Acessado em: 23 de janeiro de 2020.

LUIZ, Lilian Campagnin.; RAU, Karlan; FREITAS, Claudio Luiz de., \& PFITSCHER, Elisete Dahmer. Agenda ambiental na administração pública (a3p) e práticas de sustentabilidade: Estudo aplicado em um instituto federal de educação, ciência e tecnologia. Revista Administração Pública e Gestão Social (RAPGS), v. 5, n. 2, p. 114-134, abr.jun. 2013. Disponível em: < https://periodicos.ufv.br/apgs/article/view/4423>. Acessado em: 07 de abril de 2020.

MARCELINO, Igor Polla. Avaliação da Universidade Federal de Santa Catarina como Laboratório Vivo de Sustentabilidade. Trabalho de Conclusão do Curso de Engenharia Sanitária e Ambiental, Universidade Federal de Santa Catarina - UFSC, Florianópolis - Santa Catarina, 2016. Disponível em: $<$ https://repositorio.ufsc.br/bitstream/handle/123456789/160232/TCC\%2020152\%20lgor\%20Polla\%20Marcelino.pdf?sequence=1 >. Acessado em: 27 de outubro de 2020

MORAES, Clauciana Schmidt Bueno de; DADARIO, Andrew Maranhão Ventura; GUALTER, Leonardo Prudente Torres; NUNES, Lia Carolina Viotto; BARBOSA, Priscilla Nicacio Os Benefícios da Implantação do Sistema de Gestão Ambiental (SGA) e a Aplicação na Universidade. XVI ENGEMA - Encontro Internacional sobre Gestão Empresarial e Meio Ambiente - FEA/USP - 2014. Disponível em: <. http://www.engema.org.br/XVIENGEMA/103.pdf>. Acessado em: 25 de agosto de 2020. 
MORESI, Eduardo. Metodologia da Pesquisa, Universidade Católica de Brasília UCB, 2003. Brasília. 108 p. Disponível em: <www.inf.ufes.br/ pdcosta/ensino/2010-2metodologia-de-pesquisa/MetodologiaPesquisa-Moresi2003.pdf>. Acessado em 06 de abril de 2020.

MOURA, Manoela Maria Caron.; FRANKENBERGER, Fernanda; TORTATO, Ubiratã. Sustainability in Brazilian HEl: Practices overview. International Journal of Sustainability in Higher Education, v. 20, n. 5, 2019, p. 832-841. Emerald Publishing Limited. Disponível em: < https://doi.org/10.1108/IJSHE-01-2019-0021>. Acessado em: 08 de janeiro de 2020.

MUNCK, Luciano; MUNCK, Mariana Gomes. Musetti.; SOUZA, Rafael Borim de. Sustentabilidade Organizacional: A Proposição de uma Framework Representativa do Agir Competente para seu Acontecimento. Gerais: Revista Interinstitucional de Psicologia, 4 (2), Edição Especial, dezembro, 2011, p. 147-158. Disponível em: < https://www.researchgate.net/publication/286359938_Sustentabilidade_Organizacion al_A_Proposicao_de_uma_Framework_Representativa_do_Agir_Competente_para_ seu_Acontecimento_Organizational_Sustainability_Proposing_a_Representative_Fra mework_for_the_Occcur>. Acessado em: 23 de fevereiro de 2020.

MUNCK, Luciano; SOUZA, Rafael Borim de; ZAGUI, Cristiane. A gestão por competências e sua relação com ações voltadas à sustentabilidade. REGE-Revista de Gestão, São Paulo-SP, v. 19, n. 3, p. 371-389, jul./set. 2012. Disponível em: <https://www.sciencedirect.com/science/article/pii/S1809227616303149>. Acessado em: 23 de fevereiro de 2020.

PEREIRA, Cristina Alves. Proposta de ações sustentáveis para o Colégio Pedro II com base no modelo da agenda ambiental na administração pública (a3p). Dissertação (Mestrado em Sistemas de Gestão) - LATEC, Universidade Federal Fluminense, Niterói, 2016. Disponível em: < https://app.uff.br/riuff/handle/1/3953>. Acessado em: 23 de janeiro de 2020. 
TAUCHEN, Joel; BRANDLI, Luciana Londero. Gestão ambiental em instituições de ensino superior: modelo para implantação em campus universitário. Revista Gestão e Produção, v. 13, n. 3, p. 503-515, set/dez 2006. Disponível em: < https://www.scielo.br/scielo.php?pid=S0104-

530X2006000300012\&script=sci_arttext>. Acessado em: 27 de janeiro de 2020.

TRIGO, Aline Guimarães Monteiro; LIMA, Ricardo da Silva Xavier de; OLIVEIRA, Daniel Machado de. Índice de Sustentabilidade Socioambiental no Ensino. Revista de Administração da Universidade Federal de Santa Maria - UFSM, v. 7, Edição Especial, p. 07-22, nov. 2014. Disponível em: https://doi.org/10.5902/1983465912771. Acessado em: 23 de janeiro de 2020.

VASCONCELOS, Gislane Sampaio. Sustentabilidade socioambiental no gerenciamento dos campi da Universidade Federal do Ceará. Dissertação (Mestrado Profissional em Políticas Públicas e Gestão da Educação Superior) Universidade Federal do Ceará, Fortaleza, 2015. Disponível em: < http://www.repositorio.ufc.br/handle/riufc/13210>. Acessado em: 26 de agosto de 2020.

ZASSO, Maria Aparecida de Carvalho. As diversas concepções de desenvolvimento sustentável. In: ZASSO, Maria Aparecida de Carvalho; FERREIRA, Francesca; LUCCHESE, Osório; ATTUATI, Márcia Amarildo; FERNANDES, Sandra Beatriz Vicenci; UHDE, Leonir Terezinha. Meio Ambiente e Sustentabilidade. Rio Grande do Sul: Unijuí, 2014, p. 81-93. Disponível em: <http://bibliodigital.unijui.edu.br:8080/xmlui/bitstream/handle/123456789/3241/Meio\% 20ambiente\%20e\%20sustentabilidade.pdf?sequence $=1>$. Acessado em: 23 de fevereiro de 2020.

Enviado: Novembro, 2021.

Aprovado: Dezembro, 2021. 